Central Washington University

ScholarWorks@CWU

All Faculty Scholarship for the College of the Sciences

2-12-2018

\title{
GPS Vertical Land Motion Corrections to Sea-Level Rise Estimates in the Pacific Northwest
}

Jean-Philippe Montillet

Ecole Polytechnique Fédérale de Lausanne

Timothy I. Melbourne

Central Washington University

Walter M. Szeliga

Central Washington University

Follow this and additional works at: https://digitalcommons.cwu.edu/cotsfac

Part of the Geology Commons, and the Tectonics and Structure Commons

\section{Recommended Citation}

Montillet, J.-P., Melbourne, T. I., \& Szeliga, W. M. (2018). GPS vertical land motion corrections to sea-level rise estimates in the Pacific Northwest. Journal of Geophysical Research: Oceans, 123, 1196-1212. https://doi.org/10.1002/2017JC013257

This Article is brought to you for free and open access by the College of the Sciences at ScholarWorks@CWU. It has been accepted for inclusion in All Faculty Scholarship for the College of the Sciences by an authorized administrator of ScholarWorks@CWU. For more information, please contact scholarworks@cwu.edu. 


\section{Journal of Geophysical Research: Oceans}

\section{RESEARCH ARTICLE \\ 10.1002/2017JC013257 \\ GPS Vertical Land Motion Corrections to Sea-Level Rise Estimates in the Pacific Northwest}

Key Points:

- Sea-level rise estimated around the Pacific Northwest using 18 tide gauges

- Influence of vertical land motion on sea-level rise measurements estimated with a large network of GPS stations

- Discussion on the influence of the scale parameter in the product released by the PANGA and PBO GAGE analysis centers

\section{Correspondence to:}

J.-P. Montillet,

jean-philippe.montillet@epfl.ch

\section{Citation:}

Montillet, J.-P., Melbourne, T. I., \& Szeliga, W. M. (2018). GPS vertical land motion corrections to sea-level rise estimates in the Pacific Northwest. Journal of Geophysical Research: Oceans, 123, 1196-1212. https://doi. org/10.1002/2017JC013257

Received 12 JUL 2017 Accepted 12 JAN 2018

Accepted article online 25 JAN 2018 Published online 12 FEB 2018

\author{
J.-P. Montillet 1,2 iD, T. I. Melbourne2 (D, and W. M. Szeliga2 iD \\ ${ }^{1}$ Now at School of Engineering (EPFL STI IMT-ESPLAB), Ecole Polytechnique Fédérale de Lausanne, Neuchâtel, Switzerland, \\ ${ }^{2}$ Pacific Northwest Geodetic Array, Department of Geological Sciences, Central Washington University, Ellensburg, \\ Washington, USA
}

\begin{abstract}
We construct coastal Pacific Northwest profiles of vertical land motion (VLM) known to bias long-term tide-gauge measurements of sea-level rise (SLR) and use them to estimate absolute sea-level rise with respect to Earth's center of mass. Multidecade GPS measurements at 47 coastal stations along the Cascadia subduction zone show VLM varies regionally but smoothly along the Pacific coast and inland Puget Sound with rates ranging from +4.9 to $-1.2 \mathrm{~mm} / \mathrm{yr}$. Puget Sound VLM is characterized by uniform subsidence at relatively slow rates of -0.1 to $-0.3 \mathrm{~mm} / \mathrm{yr}$. Uplift rates of $4.5 \mathrm{~mm} / \mathrm{yr}$ persist along the western Olympic Peninsula of northwestern Washington State and decrease southward becoming nearly $0 \mathrm{~mm} / \mathrm{yr}$ south of central coastal Washington through Cape Blanco, Oregon. South of Cape Blanco, uplift increases to $1-2 \mathrm{~mm} / \mathrm{yr}$, peaks at $4 \mathrm{~mm} / \mathrm{yr}$ near Crescent City, California, and returns to zero at Cape Mendocino, California. Using various stochastic noise models, we estimate long-term ( $50-100 \mathrm{yr}$ ) relative sea-level rise rates at 18 coastal Cascadia tide gauges and correct them for VLM. Uncorrected SLR rates are scattered, ranging between $-2 \mathrm{~mm} / \mathrm{yr}$ and $+5 \mathrm{~mm} / \mathrm{yr}$ with mean $0.52 \pm 1.59 \mathrm{~mm} / \mathrm{yr}$, whereas correcting for VLM increases the mean value to $1.99 \mathrm{~mm} / \mathrm{yr}$ and reduces the uncertainty to $\pm 1.18 \mathrm{~mm} / \mathrm{yr}$, commensurate with, but approximately $17 \%$ higher than, twentieth century global mean.
\end{abstract}

\section{Introduction}

Tide-gauge measurements of sea-level rise (SLR) have long been known to be susceptible to biases originating from vertical land motion (VLM) of their reference datum caused by a wide array of solid-Earth processes. Such processes may be either regional in nature or spatially localized to the tide gauge reference point, may arise from natural or anthropogenic origins, and may appear as steady-state (linear) or transient (nonlinear) signals through time. Regional processes that are effectively linear over the century timescale scale of the longest instrumental tide gauge (TG) records include glacial isostatic adjustment (GIA) due to late Pleistocene deglaciation and interseismic tectonic strain accumulation in the absence of local earthquakes, while nonlinear processes include earthquakes, annual hydrological oscillations either stationary or nonstationary in amplitude or phase, time-dependent anthropogenic aquifer depletion or other resource extraction signals, soil compaction, climatic and ocean loading signals, and numerous others. The majority of these signals are of the same order of magnitude $(\mathrm{mm} / \mathrm{yr})$ as sea-level rise itself and cannot be generally ignored.

A variety of approaches have been implemented to correct tide-gauge measurements for VLM biases in order to best isolate long-term rate of sea-level rise rate and any accelerations therein. Foremost of these is correcting for postglacial isostatic adjustment, as first shown by Douglas (1991) and later improved upon by Mitrovica and Davis (1995) and Lambeck and Johnston (1995). While this approach significantly reduces the variance of inferred long-term TG SLR rates (Hay et al., 2015), GIA corrections are intrinsically limited by incomplete knowledge of both ice spatial distribution and timing history as well as unknown lateral variations in mantle and crustal rheology, which together complicate quantifying GIA's contribution to presentday VLM around the globe. Furthermore, GIA corrections alone do not account for the plethora of non-GIArelated VLM processes also known to bias inferred TG rate estimates. This has led to numerous alternative approaches, which range from discarding TG data clearly affected by VLM, either GIA or otherwise (Douglas, 1991), or attempting to measure the VLM bias by colocating geodetic measurements with TG installations (e.g., Burgette et al., 2013; Santamaría-Gómez et al., 2011). Wöppelmann et al. (2007, 2009) estimated a 1.61 
$\pm 0.19 \mathrm{~mm} / \mathrm{yr}$ global sea-level rise over the past century. By taking advantage of newly available global GPS radial velocity maps from Blewitt et al. (2016) and using a spatial extrapolation technique for estimating VLM of gauges that do not have a collocated GPS station, Hamlington et al. (2016) found that globally averaged VLM originating from non-GIA sources is $0.24 \pm 0.08 \mathrm{~mm} / \mathrm{yr}$ globally, or roughly $20 \%$ of the twentieth century average global SLR, based on the estimate from Ray and Douglas (2011). They find that using either several hundred global stations or the same 89 stations (used in Ray and Douglas (2011)) give similar results, but point out that the precise contribution of non-GIA VLM depends on the particular subset of tide gages and GPS stations selected. Regardless, they clearly demonstrate that non-GIA VLM is a non-negligible contribution if accuracies of $0.1 \mathrm{~mm} / \mathrm{yr}$ are desired.

The ongoing proliferation of GPS globally, which counts at least 16,000 operating stations, now allows construction of dense coastal profiles of precise vertical land motion rates within an Earth's center of mass reference frame that capture and allow correction for all solid-Earth processes, both known and unknown, that bias sea-level rise measurements made from tide-gauge data. In this paper, we derive two profiles for the Cascadia subduction zone and use them to correct long-term tide-guage sea-level rate estimations. Their smooth regional variation shows that the ongoing proliferation of high-quality GNSS stations (e.g., Blewitt et al., 2016; Meertens et al., 2015) allows VLM profiles such as these to be utilized by climate scientists without GPS expertise for much of the Earth's coastline to remove VLM biases from sea-level rate estimates made from tide-gauge measurements.

Prior work in the Pacific Northwest includes Mazzotti et al. (2007), who used 8 TG rates constrained by 8 GPS stations, from which they found a northeast Pacific regional SLR rate of $1.7 \pm 0.5 \mathrm{~mm} / \mathrm{yr}$. One primary limitation of this study is that their coastal vertical velocity estimates were not produced within a reference frame defined by Earth's center of mass, but rather relative to a single station located far from the Cascadia subduction zone that has subsequently been shown to have a long-term radial velocity with respect to Earth's center of mass in excess of $0.5 \mathrm{~mm} / \mathrm{yr}$. Moreover, the station density and duration of observations were limited at the time, which prohibited Mazzotti et al. (2007) from resolving spatial distribution of VLM. In this study, we offer substantial improvements to Mazzotti et al. (2007) in TG sea-level rise rate estimation in general and correction for VLM specifically. First, we generate coastal VLM profiles with an Earth's center of mass-fixed reference frame for the coastal Pacific Northwest from multidecade, daily GPS measurements for 47 stations located along the coastal Cascadia and the inland Puget Sound and Salish Sea. The continuous, daily measurements from which the VLM profiles are constructed capture all processes that may bias SLR rates inferred from TG data. The VLM profiles are produced within the ITRF08 reference frame (e.g., Altamimi et al., 2011) and we explore how subtleties in reference frame definition impact both VLM rate estimates and, in turn, sea-level rise estimates based on VLM corrections. With VLM profiles in hand we then estimate, using several different noise models, the long-term relative sea-level rise from 18 tide gauges whose duration of measurements span between 40 and 100 years. Uncorrected the estimates are widely scattered between -2 and $+5 \mathrm{~mm} / \mathrm{yr}$. After correction for VLM, the absolute sea-level rise rates with respect to Earth's center of mass cluster around $1.99 \pm 1.18 \mathrm{~mm} / \mathrm{yr}$ and compare well with prior estimates from earlier studies that relied on measurements with lower spatial density and shorter time series (Burgette et al., 2009; Church et al., 2004; Mazzotti et al., 2007; NRC, 2015; Wöppelmann et al., 2009).

\section{Methodology to Estimate Vertical Land Motion and Sea-Level Rise}

\subsection{Cascadia Vertical Land Motion Profiles in ITRF08}

To generate continuous VLM profiles for Cascadia, we use measurements from continuously operating GPS receivers that comprise the Pacific Northwest Geodetic Array (PANGA) (Miller et al., 1998) and EarthScope Plate Boundary Observatory (UNAVCO, 2009), computed within the ITRF 2008 reference frame (e.g., Altamimi et al., 2011). 100 GPS stations from these two combined networks effectively blanket Cascadia, from northern California through Oregon, Washington State, southwestern British Columbia and Vancouver Island. This study uses 47 stations located on or within $10 \mathrm{~km}$ of the Pacific coast and inland waters of Puget Sound and Salish Sea east of Vancouver Island. The vast majority of these GPS stations have at least 10 years of continuous observations with some exceeding 20 years of continuous observations. From these stations, long-term vertical land motion rates may be estimated, along with formal uncertainties, within the precision of a few tenths of $\mathrm{mm} / \mathrm{yr}$ (e.g., Figure 1). 


\section{QAGU Journal of Geophysical Research: Oceans}

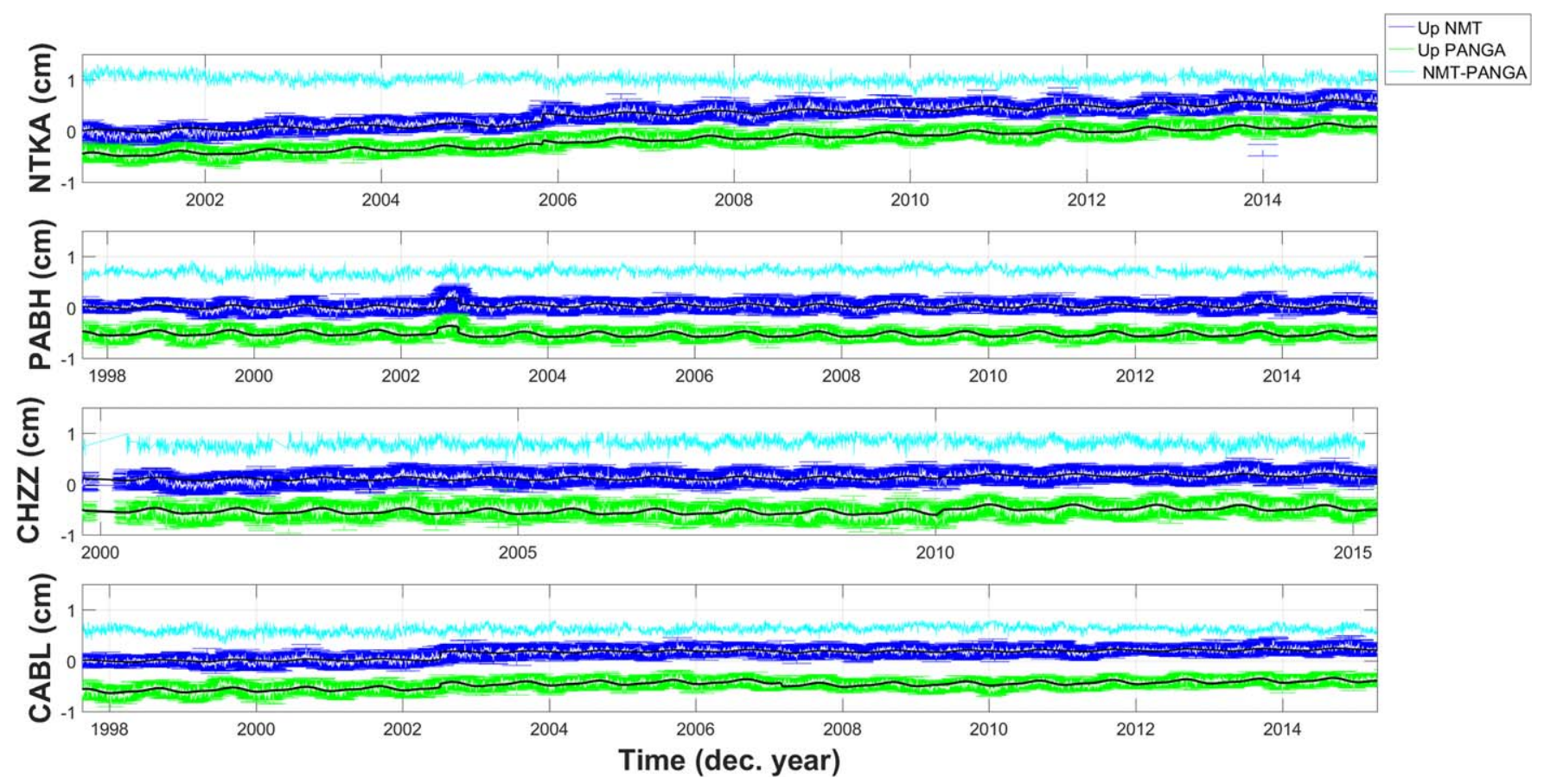

Figure 1. Vertical time series of north-to-south GPS stations NTKA, PABH, CHZZ, CABL along the Pacific Northwest coast from PANGA (green) and (PBO-)NMT (blue) processing. The black line is the estimated functional model described in section 2. PANGA and (PBO-NMT) time series are shifted knowing that they start approximately at the same point of origin at a nominated epoch. Note that the mean value is removed for the time series computed by PANGA, and the NMT ones are shifted from $-0.5 \mathrm{~cm}$ for all the stations. Overall, the results show similar geophysical features (e.g., amplitude of seasonal signal, velocity) in both time series and for each station.

For GPS data processing, raw GPS phase and code observations were point-positioned with ambiguity resolution using GIPSY/OASIS II, the GPS Inferred Positioning System/Orbit Analysis and Simulation software developed and supported by NASA Jet Propulsion Laboratory (JPL) (Zumberge et al., 1997). Satellite ephemerides, clock corrections, and wide-lane phase bias estimates were provided by JPL (Bertiger et al., 2010). In our approach, station positions are loosely constrained during initial estimation and subsequently transformed into the International Terrestrial Reference Frame (ITRF08) (e.g., Altamimi et al., 2011) using only the translation and rotation, but not scale, components of the JPL-provided Helmert transformations. The impact of choosing to use or omit the scale term in reference frame realization is discussed more fully below.

\subsection{Treatment of Temporally Correlated Noise in GPS and Tide Gage Time Series}

GPS time series have been shown repeatedly to comprise of a sum of stochastic processes and other signals arising from spatially correlated seasonal position variations, satellite orbit error, and both white and colored noise (Williams, 2003b). In addition, if they are not accounted for, biases introduced by hardware changes or seismic events affect estimated position time series and thus velocity estimates derived from them. Transient tectonic processes also can impact long-term vertical time series. Cascadia is one of many subduction zones that undergo periodic slow slip events, in this case along the Juan de Fuca-North American interplate fault, which produces resolvable vertical deformation across the GPS network (Dragert et al., 2001; Melbourne et al., 2005; Miller et al., 2002). These events are clearly observed on most GPS time series from the Cascadia fore arc as transient static deformation events associated with slow slip along the Juan de Fuca-North American plate interface. Proper modeling of these slow slip events requires a slip inversion for each event, but as far as is known these events are continuous processes related to the tectonic activity of the Earth and we make the assumption that their contribution to VLM is constant over the long-term and properly modeled as a linear process that comprises both slow earthquake offsets and long-term interseismic strain. Moreover, the effect of including all the offsets would result in an unrealistically small estimates of the background tectonic rate. As a practical matter, this results in larger uncertainties for western WA 
and BC (Figure 3b) compared with those from central and south Oregon (Figure 3c) and northern California (Figure 3d).

The functional model we use to represent time series of daily GPS positions consists of a linear trend, two sinusoidal seasonal variations with periods fixed to 1 and 0.5 years and constant phase and amplitude, along with step functions at hardware changes and known seismic events greater than $M w=6$, as follows:

$$
y_{i}=y_{0}+r t_{i}+o p_{i}+A_{1} \cos \left(2 \pi \omega_{1} t\right)+A_{2} \sin \left(2 \pi \omega_{1} t\right)+A_{3} \cos \left(2 \pi \omega_{2} t\right)+A_{4} \sin \left(2 \pi \omega_{2} t\right)+\varepsilon\left(t_{i}\right)
$$

where $\varepsilon\left(t_{i}\right)$ is the error term and $p_{i}$ is the Heaviside function $\left(p_{i}=1\right.$ if $t_{i} \geq t_{\text {off }}$, $t_{\text {off }}$ the time of occurrence of the offset). The $A_{i}$ coefficients are the amplitudes of the annual and semiannual signals, with $\omega_{1}$ and $\omega_{2}$ the phase for each periodic signal, following Szeliga et al. (2008). Effectively estimating the different terms in this equation requires a minimum of roughly 2.5 years of observation at a station Blewitt and Lavallée (2002). To ensure this, only GPS time series with more than 5 years of observations are included in this study. Given the long observation history in this region, our resulting data set has a mean station observation time length of 14 years with a maximum of 21 years of observations.

This representation is easily linearized, and the parameters included in the functional model of the GPS time series have traditionally been estimated with least squares under the assumption of Gaussiandistributed white noise. However, it has been generally accepted that the noise in GPS time series is best described as a combination of colored noise plus white noise (e.g., Bos et al., 2013; Klos et al., 2015; Langbein, 2004, 2008; Montillet et al., 2015; Williams et al., 2004; Zhang et al., 1997). The model can then be either white noise, or the combination of white and flicker noise, or white noise with flicker and randomwalk noise (Williams et al., 2004). Flicker noise and random-walk belong to the family of power-law noise (He et al., 2017; Zhang et al., 1997). Because standard least squares in the presence of colored noise results in overly small uncertainties compared to total noise amplitudes (e.g., Montillet et al., 2015; Williams, 2003a), we therefore solve for the linear coefficients in equation (1) using a maximum likelihood estimator (MLE) approach that more realistically estimates not only the parameters of our functional model but also the full noise covariance (both white and colored noise components, equation (2)) (Williams, 2003a). This approach is realized using the software package HECTOR (Bos et al., 2013b)

$$
\mathbf{C}=a_{w} \mathbf{I}+a_{p l} \mathbf{E}(\alpha)
$$

Equation (2) is the stochastic model used in our processing, with $a_{w}$ being the variance of the white noise, $a_{p l}$ the variance of the colored noise, and $\alpha$ the exponent of the colored noise (with value in the interval $[-2,-1])$. $\mathbf{E}$ is the covariance matrix of the colored noise as defined in Williams (2003a). The exponent of the colored noise is set to -1 (i.e., flicker noise). Flicker together with white noise is the model widely used for describing noise processes in long GPS time series for all three coordinate components (e.g., He et al., 2016, 2017; Mao et al., 1999; Williams et al., 2004; Zhang et al., 1997). This then reduces the computational time that is a limiting factor in using this software for long time series (Bos et al., 2008, 2013).

Long-term tide gauge records, like GPS time series, are also known to have temporally correlated noise and are treated similarly to the GPS time series. Previous users of tide gage data have employed various stochastic models to account for this temporal correlation by including the effects of using observations with different lags. Stochastic properties can be modeled with ARFIMA, ARMA (Bos et al., 2014), Generalized Gauss Markov noise model (GGM) (Bos et al., 2014). ARMA is the optimal stochastic model in time series with short-term correlations, whereas ARFIMA should be used in the presence of colored noise (or long-term correlations) due to the versatility of modeling power-law stochastic processes (e.g., Montillet \& Yu, 2015; Panas, 2001). According to Bos et al. (2008), an optimal selection of the noise model results by minimizing either the Akaike Information Criterion (AIC; Akaike, 1974) or the Bayesian Criterion (BIC; Schwarz, 1978). We estimate a linear trend corresponding to steady-state SLR, together with a seasonal signal plus noise, using noise models that include ARMA, ARFIMA, and GGM models. We also report the BIC as well as the AIC for completeness.

Figure 1 shows GPS vertical position time series over a 15 year window computed by PANGA (green) and, for comparison, time series for the same stations generated by the EarthScope Plate Boundary Observatory GAGE analysis centers (Herring et al., 2016) using the GAMIT-only solution (PBO-NMT product) rather than the combined GIPSY-GAMIT solution. The GAGE GPS product (blue) is a merged position product 


\section{CAGU Journal of Geophysical Research: Oceans}

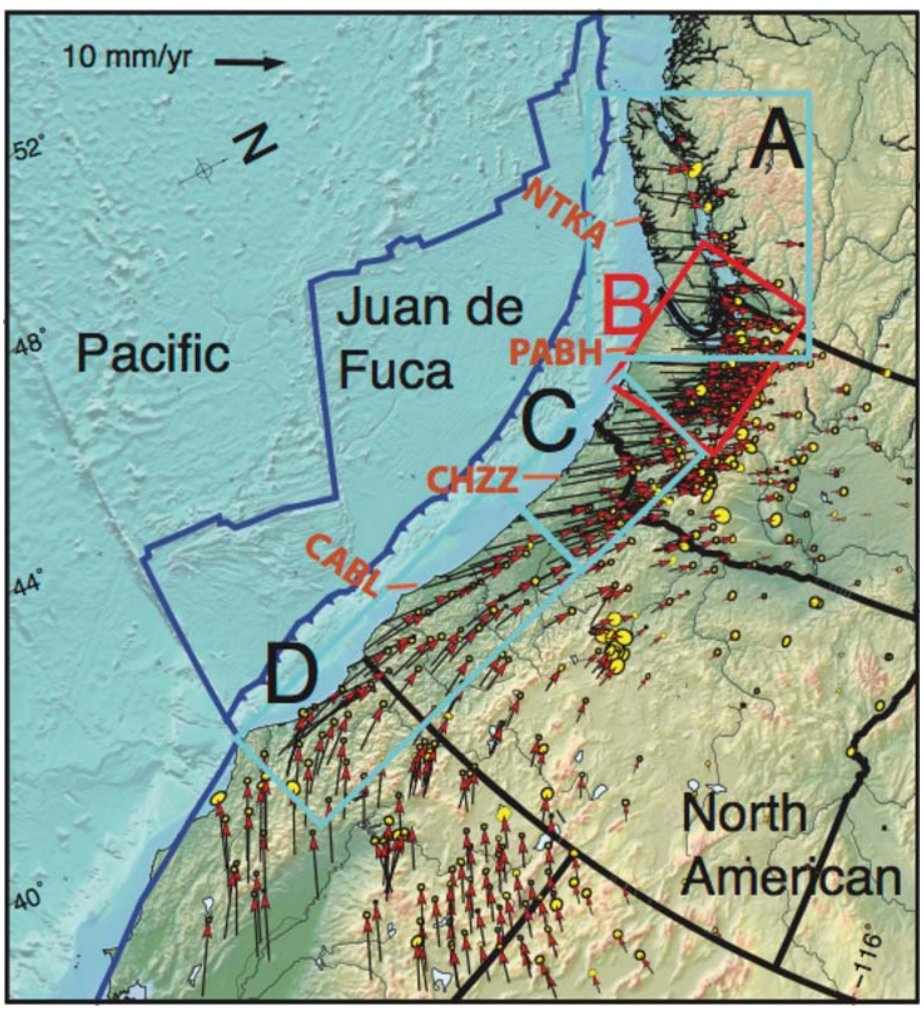

Figure 2. Horizontal velocity field (east and north component) of the Cascadia subduction zone within the NAM08 reference frame. The resultant vectors are the estimates of the steady-state (linear) term from equation (1) estimated from daily GPS positions produced by the Pacific Northwest Geodetic Array (PANGA). Horizontal positions and velocities translated into NAM08 using Euler pole location and rates from Altamimi et al. (2011). comprising point-positioned and double-differenced GPS positions weighted approximately equally and only containing Cascadia stations operated by Plate Boundary Observatory (Herring et al., 2016). The overall structure of each time series is similar, showing nearly identical geophysical signals (e.g, amplitude of seasonal signal, net long-term velocity). Daily position differences are shown in light blue.

Figure 2 shows the resultant Pacific Northwest steady-state long-term horizontal motion, in the North American 2008 (NAM08) (Herring et al., 2016) reference frame, and Figure 3 its long-term vertical velocity field, in ITRF08, which is substantially the same in vertical as NAM08. This overall pattern of deformation has been well documented during the past three decades, first using triangulation networks (Savage \& Lisowski, 1991) and later campaign and continuous GPS observations (e.g., Hyndman \& Wang, 1995; McCaffrey et al., 2007, 2013; Miller et al., 2002). The primary tectonic signal stems from subduction of the Juan de Fuca plate beneath North America at roughly $40 \mathrm{~mm} / \mathrm{yr}$ (Wilson, 1993). Along the Oregon coast and lower Washington coast, subduction is oblique, whereas off Washington (inland Puget Sound) and Vancouver Island, subduction is approximately normal to the margin. Figure 3 shows the interseismic, linear component vertical land motion, which varies regionally but smoothly, from the Brooks Peninsula of Vancouver Island at the northern end of the Cascadia margin southward to the southern terminus of the Cascadia margin at Cape Mendocino, California.

Broadly speaking, the Cascadia fore arc can be separated into three regions based on their vertical motion. Along Cascadia's northern half, all of Vancouver Island and the Olympic peninsula show high uplift rates reaching nearly $5 \mathrm{~mm} / \mathrm{yr}$ at Woss, BC and Quadra Island, BC, and with a mean uplift of around $2 \mathrm{~mm} / \mathrm{yr}$. Rapid uplift seen on Vancouver Island stems from the superposition of subduction interseismic strain and postglacial rebound, and are consistent with Mazzotti et al. (2007). Uplift rates remain as high as $4 \mathrm{~mm} / \mathrm{yr}$ along the western Olympic Peninsula of northwestern Washington State, but diminish southward to nearly zero south of central coastal Washington and remain near zero south of central coastal Washington to near the latitude of Cape Blanco, Oregon. South of Cape Blanco uplift increases again, averaging about 1-2 mm/yr, with a maximum near $4 \mathrm{~mm} / \mathrm{yr}$ at Crescent City, California, and drops back to zero at Cape Mendocino, California. In contrast, the inland waterways of the Puget Sound are characterized by subsidence at rates of -0.1 to $-0.3 \mathrm{~mm} / \mathrm{yr}$ while the Salish Sea region east of Vancouver Island is marked by uplift ranging from 1 to $4 \mathrm{~mm} / \mathrm{yr}$ (e.g., Figure 6).

As an independent check of the PANGA processing of the Cascadia GPS data, Figure 4 compares the range of rates and uncertainties for PBO stations processed by both the PANGA and PBO GAGE Analysis centers. The two centers' numbers compare well within error. Table 1 lists the PANGA, PBO-NMT, and Mazzotti et al. (2007) uplift estimates. Overall for the PANGA processing, $67 \%$ of the stations processed here show the same rates within 1 sigma and 97\% show the same rate within 2 sigma, whereas for the PBO-NMT processing $71 \%$ of the results are within 1 sigma and $97 \%$ within 2 sigma. Looking at this table, the mean values estimated using the first eight stations, are $1.12 \pm 1.06$ and $1.34 \pm 1.07 \mathrm{~mm} / \mathrm{yr}$ for PBO-NMT and PANGA, respectively, whereas the mean value is equal to $1.62 \pm 1.20 \mathrm{~mm} / \mathrm{yr}$ using the estimates from Mazzotti et al. (2007), which is 23\% larger on average. This is to be expected, given that Mazzotti et al. (2007) were based on shorter time series ( $<7 \mathrm{yrs}$ ) modeled with least squares in the IGS08 reference frame, which certainly impacts the noise properties of the time series compared to ITRF08. Also due to the large discrepancy of the uplifts estimates between the two products at some stations (e.g., PTRF, BLYN), one can wonder about the efficiency of the choice of the stochastic model in the processing of the GPS time series. Thus, we cannot exclude the possibility of outliers in our estimates.

While the VLM rates are measured along the coast at 47 disparate GPS stations that their inferred rates are smoothly varying allows their interpolation to generate continuous VLM profiles. We use a linear 


\section{QAGU Journal of Geophysical Research: Oceans}
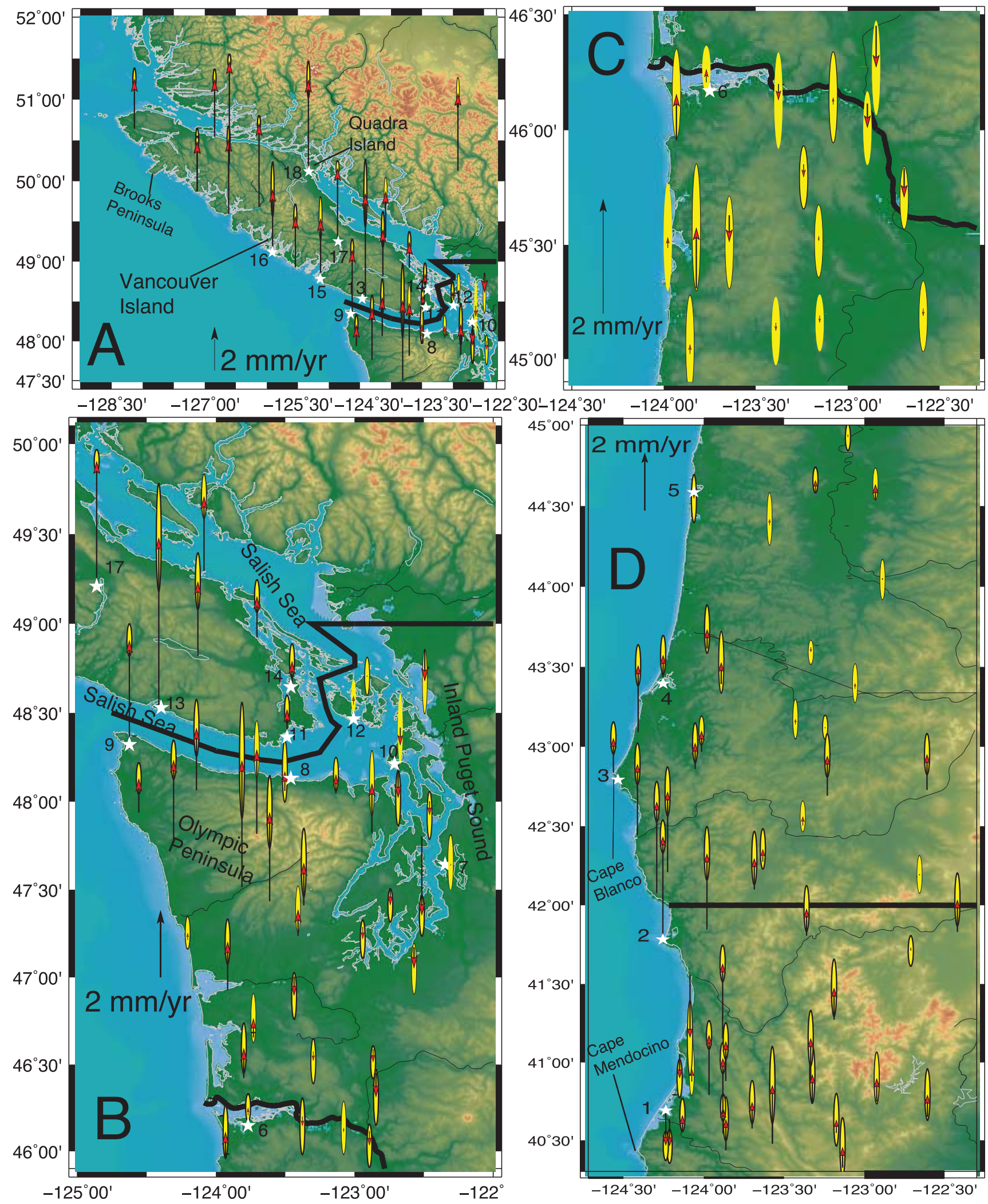

Figure 3. Vertical land motion of the Cascadia subduction zone including British Columbia, Washington, Oregon, and Northern California. The figures are the zoom defined by the boxes in the previous figure. White stars denote the location of 18 tide gauges used in this study. Only coastal stations are used to derive the vertical land motion profiles shown in Figures 5 and 6 . Note the change of length of $2 \mathrm{~mm} / \mathrm{yr}$ scale bar between different boxes. Also the letters (A, B, C, D) refer to the previous figure. 

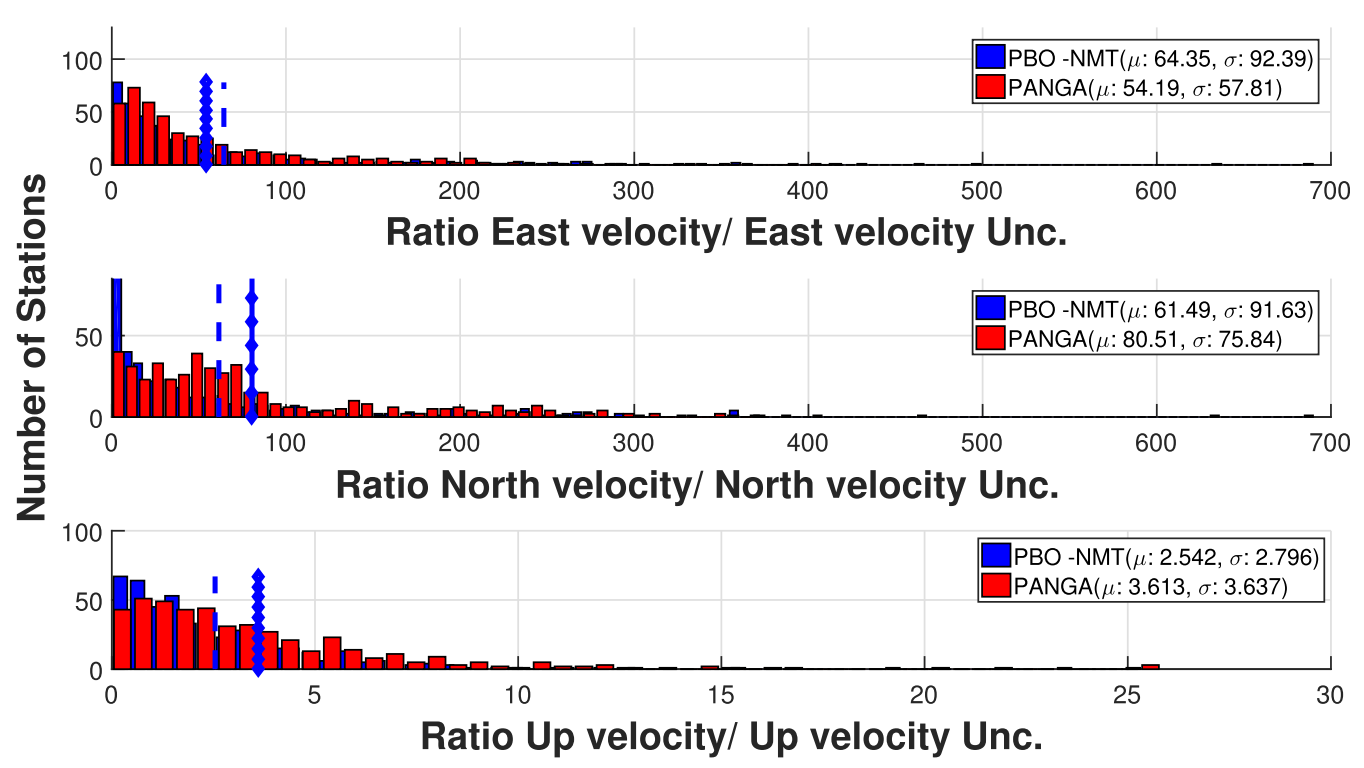

Figure 4. Histogram of the ratios in absolute value of velocity estimate divided by associated uncertainty for PBO-NMT (blue) and PANGA (red) results. The dotted line is the mean value for the histogram of PANGA ratios, whereas the dashed line is the mean value for the PBO-NMT ratios. Note that we display the ratio for the North and East coordinates in order to compare the values for the Up coordinate and the other two components.

interpolation, and the resultant profiles are shown in Figure 5 for the Pacific coast and Figure 6 along Puget Sound and the Salish Sea of British Columbia. We use these VLM profiles to both correct tide gages that do not have GPS colocated with them or may be utilized for SLR adaptation planning by communities where local GPS is not available, as discussed below.

\section{Tide Gauge Estimates of Uncorrected Relative Sea-Level Rise}

To estimate relative sea-level rise rates uncorrected for VLM (RSLR), monthly records from 18 stations were selected along the Pacific Northwest coast between the latitudes $40^{\circ}$ and $51^{\circ}$ using raw data downloaded from the Permanent Service for Mean Sea Level (Rickards, 2015), which in some cases have nearly 115 years of measurements (e.g., Seattle). The linear rates corresponding to long-term SLR in the presence of colored and other noise sources are estimated as described above. Table 2 shows different estimates of the uncorrected RSLR for five tide gauges along coastal Pacific Northwest, Puget Sound, and Salish Sea. As shown in Tables 2 and 3, our RSLR results are generally closer to the values estimated from the NRC group (NRC, 2015). The ARFIMA model seems to produce smaller uncertainties (using the AIC). Assuming that the AIC selects the lags more optimally than the BIC, it may suggest the presence of long memory processes (i.e., power-law noise) in the TG time series, which should be better accounted for using this stochastic model than using a model such as the ARMA. Even though we have circumvented the bias due to mismodeling the TG measurements using information criteria, we acknowledge that estimated RSL values are sensitive to the choice of record length of the tide gauges selected following previous studies (Douglas, 1991) and that unmodeled multidecade transients will impact rate estimates differently based on both the time series duration and the structure of any known long-term transients. Note that the optimality of model selection using information criteria is an active research area within the geophysical community (He et al., 2017).

Figure 7 shows resultant RSLR (in red) as estimated from the tide gauge reference mark uncorrected for VLM, as a function of latitude. RSLR values along coastal Cascadia are fairly scattered, ranging from -2 to $+5 \mathrm{~mm} / \mathrm{yr}$, as is to be expected given both the highly variable tectonic and GIA activity as well as the intrinsic scatter of average sea level itself due to the many hydrodynamic processes that control yearly variation in apparent sea level (Church et al., 2004). The RSLR estimates agree well with a variety of recent studies (e.g., Mazzotti et al., 2007; NRC, 2015; Sweet et al., 2014), and their dependence on specific noise model is relatively minor ( 0.1 sigma confidence level), as is whether the AIC or BIC criteria is minimized. In all cases, uncertainties are computed using the MLE as implemented in the HECTOR software (Bos et al., 
Table 1

GPS-Derived Vertical Land Motion Rate Estimates for Reference Stations Included in PANGA, PBO, and Mazzotti et al. (2007) Processing

\begin{tabular}{|c|c|c|c|c|c|c|c|c|}
\hline & \multirow[b]{2}{*}{ Lat. } & \multirow[b]{2}{*}{ Lon. } & \multicolumn{2}{|c|}{ PANGA } & \multicolumn{2}{|c|}{ NMT } & \multicolumn{2}{|c|}{$\begin{array}{l}\text { Mazzotti et al. } \\
\text { (2007) }\end{array}$} \\
\hline & & & $\mu$ & $\sigma$ & $\mu$ & $\sigma$ & $\mu$ & $\Sigma$ \\
\hline ALBH & 48.39 & -123.49 & 0.69 & 0.16 & 0.78 & 0.27 & 1.1 & 0.9 \\
\hline PGC5 & 48.65 & -123.45 & 0.77 & 0.21 & 0.05 & 0.45 & 1.80 & 1.0 \\
\hline NANO & 49.29 & -124.08 & 2.23 & 0.27 & 1.77 & 0.36 & 2.50 & 0.90 \\
\hline UCLU & 48.92 & -125.54 & 2.46 & 0.23 & 1.89 & 0.33 & 2.70 & 0.90 \\
\hline DRAO & 49.32 & -119.62 & 1.01 & 0.21 & 1.15 & 0.34 & 1.20 & 0.70 \\
\hline SC02 & 48.55 & -123.01 & 0.26 & 0.20 & 0.30 & 0.36 & 0.80 & 1.30 \\
\hline SEAT & 47.65 & -122.31 & 0.09 & 0.33 & -0.21 & 0.31 & -0.60 & 0.90 \\
\hline NEAH & 48.29 & -124.62 & 3.24 & 0.19 & 3.20 & 0.30 & 3.50 & 1.00 \\
\hline PCOL & 47.17 & -122.57 & -0.64 & 0.31 & -0.64 & 0.34 & & \\
\hline P423 & 47.29 & -122.94 & -0.37 & 0.23 & -0.91 & 0.29 & & \\
\hline RPT1 & 47.39 & -122.37 & -1.83 & 0.39 & $\mathrm{NaN}$ & $\mathrm{NaN}$ & & \\
\hline KTBW & 47.55 & -122.79 & -0.50 & 0.20 & -0.44 & 0.26 & & \\
\hline P426 & 47.80 & -122.51 & -2.36 & 0.25 & -2.60 & 4.12 & & \\
\hline P437 & 48.00 & -122.46 & -0.42 & 0.29 & -1.38 & 0.66 & & \\
\hline BLYN & 48.02 & -122.93 & 1.85 & 1.53 & -2.92 & 2.43 & & \\
\hline P435 & 48.06 & -123.50 & 0.59 & 0.37 & 0.10 & 0.35 & & \\
\hline COUP & 48.22 & -122.68 & -1.05 & 0.33 & 1.10 & 2.59 & & \\
\hline WHD1 & 48.31 & -122.69 & -0.53 & 0.84 & $\mathrm{NaN}$ & $\mathrm{NaN}$ & & \\
\hline P439 & 48.71 & -122.91 & -0.01 & 0.23 & -0.29 & 0.41 & & \\
\hline SCO4 & 48.92 & -123.70 & 1.23 & 0.19 & 1.03 & 0.22 & & \\
\hline PTAL & 49.26 & -124.86 & 3.48 & 0.14 & 0.04 & 0.55 & & \\
\hline GLDR & 49.68 & -126.13 & 4.01 & 0.53 & 3.02 & 0.57 & & \\
\hline ELIZ & 49.87 & -127.13 & 2.46 & 0.22 & 2.57 & 0.35 & & \\
\hline QUAD & 50.13 & -125.33 & 4.34 & 0.35 & 3.85 & 0.44 & & \\
\hline WOST & 50.21 & -126.60 & 5.31 & 2.35 & $\mathrm{NaN}$ & $\mathrm{NaN}$ & & \\
\hline BCOV & 50.54 & -126.84 & 2.76 & 0.19 & 3.55 & 0.65 & & \\
\hline HOLB & 50.64 & -128.13 & 2.39 & 0.21 & 0.87 & 0.98 & & \\
\hline P161 & 40.64 & -124.21 & -0.95 & 0.24 & -1.47 & 0.34 & & \\
\hline P159 & 40.50 & -124.28 & -0.83 & 0.25 & -1.58 & 0.28 & & \\
\hline P162 & 40.69 & -124.24 & -1.22 & 0.24 & -1.59 & 0.29 & & \\
\hline TRND & 41.05 & -124.15 & -0.85 & 0.27 & -0.70 & 0.28 & & \\
\hline P316 & 41.56 & -124.08 & -2.18 & 0.53 & -2.06 & 0.59 & & \\
\hline PTSG & 41.78 & -124.25 & 3.56 & 0.23 & 3.03 & 0.25 & & \\
\hline P734 & 42.07 & -124.29 & 3.17 & 0.28 & 2.03 & 0.36 & & \\
\hline P362 & 42.21 & -124.23 & 2.79 & 0.34 & 2.05 & 0.41 & & \\
\hline P733 & 42.44 & -124.41 & 2.47 & 0.29 & 0.89 & 0.33 & & \\
\hline CABL & 42.84 & -124.56 & 1.21 & 0.22 & 1.43 & 0.24 & & \\
\hline P364 & 43.09 & -124.41 & 2.32 & 0.29 & 1.73 & 0.44 & & \\
\hline P365 & 43.39 & -124.25 & 0.99 & 0.27 & 0.01 & 0.40 & & \\
\hline P366 & 43.61 & -123.98 & 0.67 & 0.34 & -0.60 & 0.34 & & \\
\hline P367 & 44.59 & -124.06 & -0.22 & 0.34 & -0.81 & 0.39 & & \\
\hline P395 & 45.02 & -123.86 & 0.17 & 0.35 & -0.15 & 0.34 & & \\
\hline P396 & 45.31 & -123.82 & 1.06 & 0.45 & 0.16 & 0.41 & & \\
\hline $\mathrm{CHZZ}$ & 45.48 & -123.98 & 0.19 & 0.38 & 0.81 & 0.24 & & \\
\hline TPW2 & 46.21 & -123.77 & 0.23 & 0.16 & 0.48 & 0.22 & & \\
\hline P398 & 46.92 & -123.92 & 1.45 & 0.27 & 0.55 & 0.41 & & \\
\hline PABH & 47.21 & -124.20 & 0.22 & 0.19 & 0.23 & 0.30 & & \\
\hline P402 & 47.77 & -124.31 & 2.47 & 0.24 & 1.66 & 0.45 & & \\
\hline PTRF & 48.54 & -124.41 & 4.99 & 0.65 & 1.66 & 1.01 & & \\
\hline BAMF & 48.84 & -125.13 & 2.69 & 0.42 & 1.76 & 0.44 & & \\
\hline TFNO & 49.15 & -125.91 & 2.86 & 0.53 & 1.47 & 0.46 & & \\
\hline NTKA & 49.59 & -126.62 & 3.58 & 0.24 & 4.27 & 0.44 & & \\
\hline
\end{tabular}

Note. $\mu$ is the estimated velocity and $\sigma$ is the associated uncertainty. Uncertainties are one sigma. PANGA and PBONMT results are computed using HECTOR. NaN means that the station was not available. 


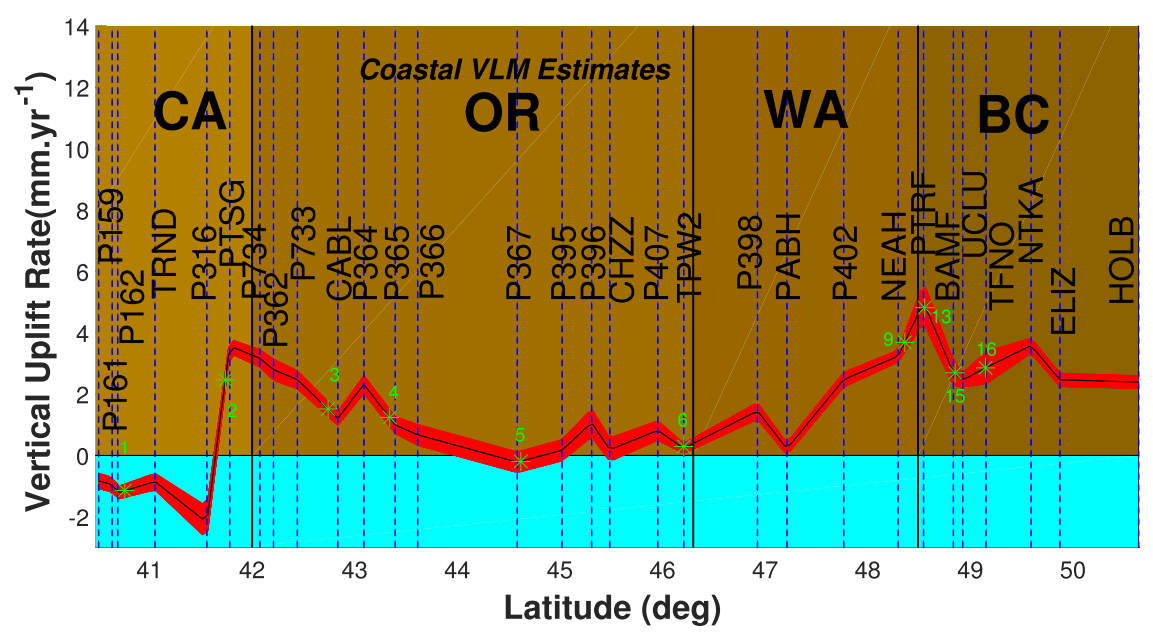

Figure 5. Interpolated long-term steady-state VLM in the Pacific Coast (Washington (WA), Oregon (OR), California (CA), and British Columbia (BC)). Note that the red band is the interpolated uncertainties. The tide gauges are localized by a green star together with their associated number.

2013b), which produces values generally larger than least squares and is less sensitive to anomalies such as those produced during windy or stormy time periods. The biggest outlier rate, at Astoria, Oregon lies $10 \mathrm{~km}$ from the coast up the Columbia River estuary. This station has uncertainties larger than the computed linear trend and we infer that the river itself likely controls much of apparent sea level fluctuation, consistent with Mazzotti et al. (2007) and Sweet et al. (2014). We also omit tide gauge observations close to GPS station $\mathrm{CHZZ}$ because of the overall low quality of the raw tide-gauge measurements.

Finally, we can also compare with the results from Burgette et al. (2009) at several sites. However, this study estimates the RSLR comparing results from a standard least squares and the Hildreth-Lu formula which consists in a linear rate with a first-order autocorrelation parameter (see Appendix B in Burgette et al. (2009)). At Crescent city, the RSLR is $-0.71 \pm 0.18 \mathrm{~mm} / \mathrm{yr}$, which is the only result close to our work (e.g., Table 2, ARFIMA (BIC) $-0.77 \pm 0.3 \mathrm{~mm} / \mathrm{yr}$ ). All the other results are much smaller than our estimates ranging from $0.9 \mathrm{~mm} / \mathrm{yr}$ (P. Orford) to $0.2 \mathrm{~mm} / \mathrm{yr}$ (Charleston, OR). The difference between this study and our result can be explained partially with the modeling approach where we take into account a full stochastic and deterministic model to model the TG time series. However, Burgette et al. (2009) includes TG time series with less

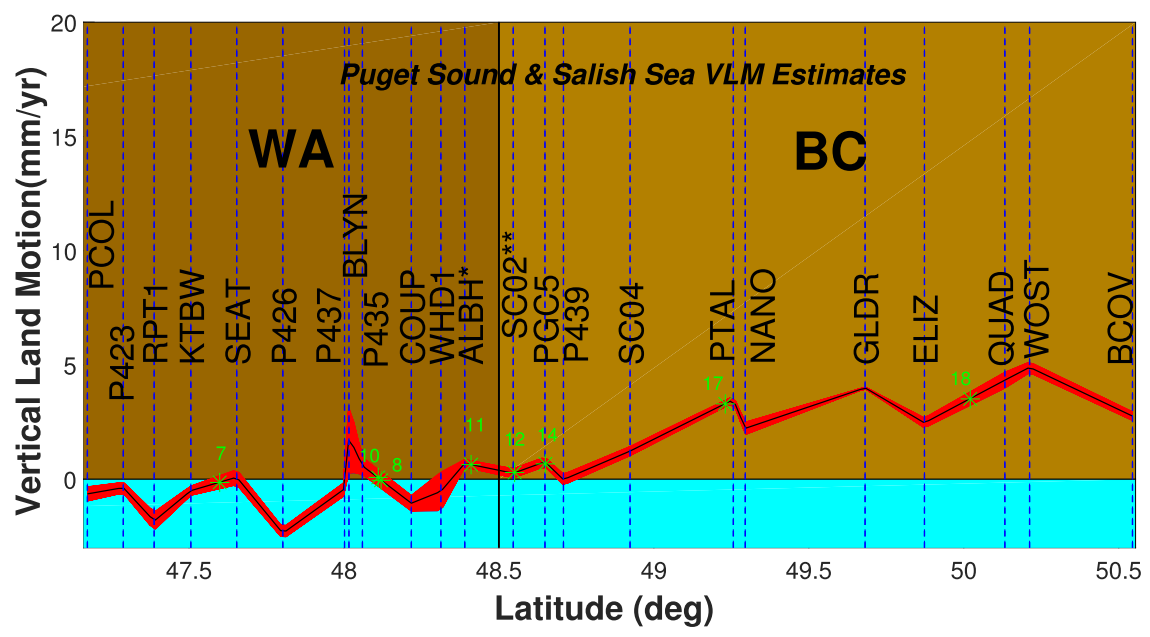

Figure 6. Interpolated long-term steady-state VLM in Puget Sound-Salish Sea corridors in Washington State (WA) and British Columbia (BC). The red band is the interpolated uncertainties. Note that station with $\left(^{*}\right)$ is in BC and $\left(^{* *}\right)$ in WA. The confusion is due to the very close latitudes of the stations at the border between BC and Washington State. The tide gauges are localized by a green star together with their associated number. 
Table 2

Estimation of the Rate of Relative Sea-Level Rise (RSLR) at Various Stations Around Pacific Northwest

\begin{tabular}{|c|c|c|c|c|}
\hline \multirow[b]{2}{*}{ Source } & \multirow[b]{2}{*}{ Tide gauge } & \multirow[b]{2}{*}{ Period (date/yr) } & \multicolumn{2}{|c|}{ Rate SLR (mm/yr) } \\
\hline & & & $\mu$ & $\sigma$ \\
\hline Douglas (1991) & Friday H., WA & 1930-1980 & 0.6 & N/A \\
\hline Mazzotti et al. (2007) & Friday H., WA & 62 year & 0.9 & 0.3 \\
\hline Sweet et al. (2014) & Friday H., WA & 1934-2006 & 1.13 & 0.33 \\
\hline NRC (2015) & Friday H., WA & 1934-2008 & 1.04 & $\mathrm{~N} / \mathrm{A}$ \\
\hline Our Study & Friday H., WA & 1934-2014 & & \\
\hline (AIC) $\operatorname{ARMA}(4,0)$ & & & 1.07 & 0.18 \\
\hline (AIC) ARFIMA $(3,-0.50 \pm 0.11,0)$ & & & 1.05 & 0.09 \\
\hline (AIC) GGM & & & 1.07 & 0.19 \\
\hline$(\mathrm{BIC}) \operatorname{ARMA}(1,1)$ & & & 1.07 & 0.18 \\
\hline (BIC) ARFIMA $(1,-0.65 \pm 0.06,1)$ & & & 1.05 & 0.08 \\
\hline (BIC) GGM & & & 1.07 & 0.19 \\
\hline Douglas (1991) & Neah Bay, WA & 1930-1980 & -1.6 & $\mathrm{~N} / \mathrm{A}$ \\
\hline Mazzotti et al. (2007) & Neah Bay, WA & $44 \mathrm{yr}$ & -1.6 & 0.6 \\
\hline Wöppelmann et al. (2009) & Neah Bay, WA & $65 \mathrm{yr}$ & -1.59 & 0.22 \\
\hline Sweet et al. (2014) & Neah Bay, WA & 1934-2006 & -1.63 & 0.36 \\
\hline NRC (2015) & Neah Bay, WA & 1934-2008 & -1.77 & $\mathrm{~N} / \mathrm{A}$ \\
\hline Our Study & Neah Bay, WA & 1934-2014 & & \\
\hline (AIC) $\operatorname{ARMA}(3,0)$ & & & -1.76 & 0.19 \\
\hline (AIC) ARFIMA $(1,-0.65 \pm 0.12,2)$ & & & -1.79 & 0.10 \\
\hline (AIC) GGM & & & -1.76 & 0.21 \\
\hline$(\mathrm{BIC}) \operatorname{ARMA}(1,1)$ & & & -1.76 & 0.19 \\
\hline (BIC) ARFIMA $(1,0.17 \pm 0.05,0)$ & & & -1.74 & 0.30 \\
\hline (BIC) GGM & & & -1.76 & 0.21 \\
\hline Douglas (1991) & Seattle, WA & 1930-1980 & 2.50 & $\mathrm{~N} / \mathrm{A}$ \\
\hline Mazzotti et al. (2007) & Seattle, WA & $92 \mathrm{yr}$ & 2.20 & 0.20 \\
\hline Wöppelmann et al. (2009) & Seattle, WA & $104 \mathrm{yr}$ & 2.06 & 0.11 \\
\hline Sweet et al. (2014) & Seattle, WA & 1898-2006 & 2.06 & 0.17 \\
\hline NRC (2015) & Seattle, WA & 1934-2008 & 2.01 & $\mathrm{~N} / \mathrm{A}$ \\
\hline Our Study & Seattle, WA & 1934-2014 & & \\
\hline (AIC) $\operatorname{ARMA}(1,2)$ & & & 2.01 & 0.11 \\
\hline (AIC) ARFIMA $(0,0.15 \pm 0.04,4)$ & & & 1.97 & 0.15 \\
\hline (AIC) GGM & & & 2.01 & 0.19 \\
\hline$(\mathrm{BIC}) \operatorname{ARMA}(1,1)$ & & & 2.00 & 0.10 \\
\hline (BIC) ARFIMA $(1,0.24 \pm 0.04,0)$ & & & 1.96 & 0.20 \\
\hline (BIC) GGM & & & 2.01 & 0.19 \\
\hline Douglas (1991) & Astoria, OR & 1930-1980 & -0.40 & $\mathrm{~N} / \mathrm{A}$ \\
\hline Mazzotti et al. (2007) & Astoria, OR & 77 year & -0.40 & 0.30 \\
\hline Sweet et al. (2014) & Astoria, OR & 1925-2006 & -0.31 & 0.40 \\
\hline NRC (2015) & Astoria, OR & 1925-2008 & -0.38 & $\mathrm{~N} / \mathrm{A}$ \\
\hline Our Study & Astoria, OR & 1925-2014 & & \\
\hline (AIC) $\operatorname{ARMA}(3,3)$ & & & -0.26 & 0.22 \\
\hline (AIC) ARFIMA $(3,0.09 \pm 0.12,0)$ & & & -0.31 & 0.11 \\
\hline (AIC) GGM & & & -0.25 & 0.24 \\
\hline$(\mathrm{BIC}) \mathrm{ARMA}(1,0)$ & & & -0.26 & 0.21 \\
\hline (BIC) ARFIMA $(0,0.27 \pm 0.04,1)$ & & & -0.22 & 0.40 \\
\hline (BIC) GGM & & & -0.25 & 0.24 \\
\hline Douglas (1991) & Crescent, CA & 1930-1980 & -0.9 & $\mathrm{~N} / \mathrm{A}$ \\
\hline Sweet et al. (2014) & Crescent, CA & 1933-2006 & -0.65 & 0.36 \\
\hline NRC (2015) & Crescent, CA & 1933-2008 & -0.73 & $\mathrm{~N} / \mathrm{A}$ \\
\hline Our Study & Crescent, CA & 1933-2014 & & \\
\hline (AIC) $\operatorname{ARMA}(4,0)$ & & & -0.81 & 0.19 \\
\hline (AIC) ARFIMA $(3,-0.59 \pm 0.11,0)$ & & & -0.80 & 0.10 \\
\hline (AIC) GGM & & & -0.81 & 0.20 \\
\hline (BIC) $\operatorname{ARMA}(1,0)$ & & & -0.82 & 0.16 \\
\hline (BIC) ARFIMA $(1,0.19 \pm 0.06,0)$ & & & -0.77 & 0.30 \\
\hline (BIC) GGM & & & -0.81 & 0.20 \\
\hline
\end{tabular}

Note. For each noise model (ARMA(p,q), ARFIMA(p,d,q), GGM), the optimum lags $p$ and $q$ are selected either by minimizing the AIC or BIC (Burnham \& Anderson, 2002). Our results are compared with the previous studies Douglas (1991), Mazzotti et al. (2007), Wöppelmann et al. (2009), Sweet et al. (2014) and NRC (2015). $\mu$ is the estimated RSLR with $\sigma$ the associated uncertainty. Uncertainties are one sigma. 


\section{QAGU Journal of Geophysical Research: Oceans}

Table 3

Estimation of the Relative SL (RSL) Rise and Corrected RSL Rise With Interpolated GPS Uplift Velocities

\begin{tabular}{|c|c|c|c|c|c|c|c|c|c|c|c|c|c|c|c|c|c|c|}
\hline \multirow[b]{2}{*}{$\sharp$} & \multirow{2}{*}{$\begin{array}{c}\text { Tide } \\
\text { Gauge }\end{array}$} & \multirow[b]{2}{*}{ Lat. } & \multirow[b]{2}{*}{ Long. } & \multirow{2}{*}{$\begin{array}{c}\text { Period } \\
(\text { date } / \mathbf{y r})\end{array}$} & \multicolumn{2}{|c|}{$\begin{array}{l}\text { (BIC)RSLR } \\
\text { ARMA }\end{array}$} & \multicolumn{2}{|c|}{$\begin{array}{l}\text { (BIC)RSLR } \\
\text { ARFIMA }\end{array}$} & \multicolumn{2}{|c|}{$\begin{array}{c}\text { (BIC)RSLR } \\
\text { GGM }\end{array}$} & \multicolumn{2}{|c|}{$\begin{array}{c}\text { VLM } \\
\text { (Interpolated) }\end{array}$} & \multicolumn{2}{|c|}{$\begin{array}{c}\text { ASLR } \\
\text { (ARMA) }\end{array}$} & \multicolumn{2}{|c|}{$\begin{array}{c}\text { ASLR) } \\
\text { (ARFIMA) }\end{array}$} & \multicolumn{2}{|c|}{$\begin{array}{l}\text { ASLR } \\
\text { (GGM) }\end{array}$} \\
\hline & & & & & $\mu$ & $\sigma$ & $M$ & $\sigma$ & $\mu$ & $\sigma$ & $\mu$ & $\sigma$ & $\mu$ & $\sigma$ & $\mu$ & $\sigma$ & $\mu$ & $\Sigma$ \\
\hline 18 & Campbell R., BC & 50.02 & -125.23 & $1958-2015$ & -1.81 & 0.48 & -1.84 & 0.33 & -1.81 & 0.53 & 3.52 & 0.29 & 1.71 & 0.40 & 1.68 & 0.31 & 1.71 & 0.43 \\
\hline 17 & P. Alberni, BC & 49.23 & -124.82 & 1947-1997 & -0.62 & 0.58 & -0.66 & 0.87 & -0.64 & 0.74 & 3.31 & 0.14 & 2.69 & 0.42 & 2.65 & 0.62 & 2.67 & 0.53 \\
\hline 16 & Tofino, BC & 49.15 & -125.91 & 1909-2015 & -1.08 & 0.38 & -1.15 & 0.24 & -1.10 & 0.13 & 2.86 & 0.50 & 1.78 & 0.44 & 1.71 & 0.39 & 1.76 & 0.36 \\
\hline 15 & Bamfield, BC & 48.85 & -125.13 & 1969-2015 & -0.28 & 0.43 & -0.2 & 0.74 & -0.27 & 0.53 & 2.69 & 0.38 & 2.41 & 0.41 & 2.49 & 0.59 & 2.42 & 0.46 \\
\hline 14 & Patricia B., BC & 48.65 & -123.45 & $1966-2015$ & 0.52 & 0.78 & 0.76 & 1.11 & 0.52 & 0.78 & 0.68 & 0.21 & 1.20 & 0.57 & 1.44 & 0.80 & 1.20 & 0.57 \\
\hline 13 & P. Renfrew, BC & 48.55 & -124.42 & 1957-1997 & 0.83 & 1.22 & 0.01 & 1.7 & 0.01 & 1.53 & 4.82 & 0.63 & 5.65 & 0.97 & 4.83 & 1.28 & 4.83 & 1.17 \\
\hline 12 & Friday Har., WA & 48.55 & -123.01 & $1934-2014$ & 1.07 & 0.18 & 1.05 & 0.07 & 1.07 & 0.19 & 0.30 & 0.20 & 1.37 & 0.19 & 1.35 & 0.15 & 1.37 & 0.19 \\
\hline 11 & Victoria, BC & 48.41 & -123.36 & $1909-2015$ & 0.7 & 0.13 & 0.74 & 0.06 & 0.7 & 0.14 & 0.64 & 0.36 & 1.34 & 0.27 & 1.38 & 0.26 & 1.34 & 0.27 \\
\hline 10 & P. Townsend, WA & 48.11 & -122.76 & $1972-2015$ & 1.67 & 0.52 & 1.76 & 0.76 & 1.71 & 0.57 & 0.06 & 0.36 & 1.73 & 0.44 & 1.82 & 0.59 & 1.77 & 0.48 \\
\hline 09 & Neah Bay, WA & 48.36 & -124.61 & 1930-1980 & -1.76 & 0.19 & -1.74 & 0.30 & -1.76 & 0.21 & 3.68 & 0.31 & 1.92 & 0.26 & 1.94 & 0.30 & 1.92 & 0.26 \\
\hline 08 & P. Angeles, WA & 48.12 & -123.44 & $1975-2015$ & -0.06 & 0.51 & 0.15 & 0.87 & 0.01 & 0.66 & -0.04 & 0.36 & -0.10 & 0.44 & 0.11 & 0.67 & -0.03 & 0.53 \\
\hline 07 & Seattle, WA & 47.60 & -122.33 & $1934-2014$ & 2.00 & 0.10 & 1.96 & 0.20 & 2.01 & 0.12 & -0.12 & 0.28 & 1.88 & 0.21 & 1.84 & 0.24 & 1.89 & 0.21 \\
\hline 06 & Astoria, OR & 46.21 & -123.77 & $1925-2014$ & -0.26 & 0.21 & -0.22 & 0.40 & -0.25 & 0.24 & 0.28 & 0.18 & 0.02 & 0.20 & 0.06 & 0.31 & 0.03 & 0.21 \\
\hline 05 & South Beach, OR & 44.62 & -124.04 & $1967-2014$ & 2.25 & 0.50 & 2.28 & 0.72 & 2.27 & 0.56 & -0.19 & 0.34 & 2.06 & 0.42 & 2.09 & 0.56 & 2.08 & 0.46 \\
\hline 04 & Charleston II, OR & 43.34 & -124.32 & $1970-2015$ & 0.88 & 0.53 & 0.96 & 0.73 & 0.86 & 0.53 & 1.23 & 0.28 & 2.11 & 0.42 & 2.19 & 0.55 & 2.09 & 0.42 \\
\hline 03 & P. Orford, OR & 42.74 & -124.49 & $1985-2015$ & 0.94 & 0.83 & 1.38 & 1.35 & 1.06 & 0.97 & 1.52 & 0.24 & 2.46 & 0.61 & 2.90 & 0.97 & 2.58 & 0.71 \\
\hline 02 & Crescent, CA & 41.74 & -124.18 & $1933-2014$ & -0.83 & 0.16 & -0.77 & 0.30 & -0.80 & 0.20 & 2.46 & 0.29 & 1.63 & 0.23 & 1.69 & 0.29 & 1.66 & 0.25 \\
\hline 01 & Humboldt, CA & 40.76 & -124.22 & $1985-2015$ & 5.06 & 0.92 & 5.63 & 1.48 & 5.19 & 1.02 & -1.15 & 0.22 & 3.91 & 0.67 & 4.48 & 1.05 & 4.04 & 0.74 \\
\hline
\end{tabular}

Note. Uncertainties (grey) are one sigma. The field ID refers to the numbers labeling the tide gauges in Figure 3 . All rates and uncertainties are in mm/yr.

recent data and historic data not included here, together with corrections of local datum at some TG. This study does not include those corrections.

\section{Absolute Sea-Level Rise in ITRF08}

Absolute sea-level rise (ASLR) is the sum of uncorrected sea-level rise as estimated from tide-gauge time series alone (RSLR) added to (corrected for) the vertical land motion measurements derived from the GPS measurements. To compute ASLR, we use the interpolated value closest to each tide gage. These criteria allow us to correct 18 tide gauges (i.e., Table 3 ) with the vertical land motions computed above. We use the
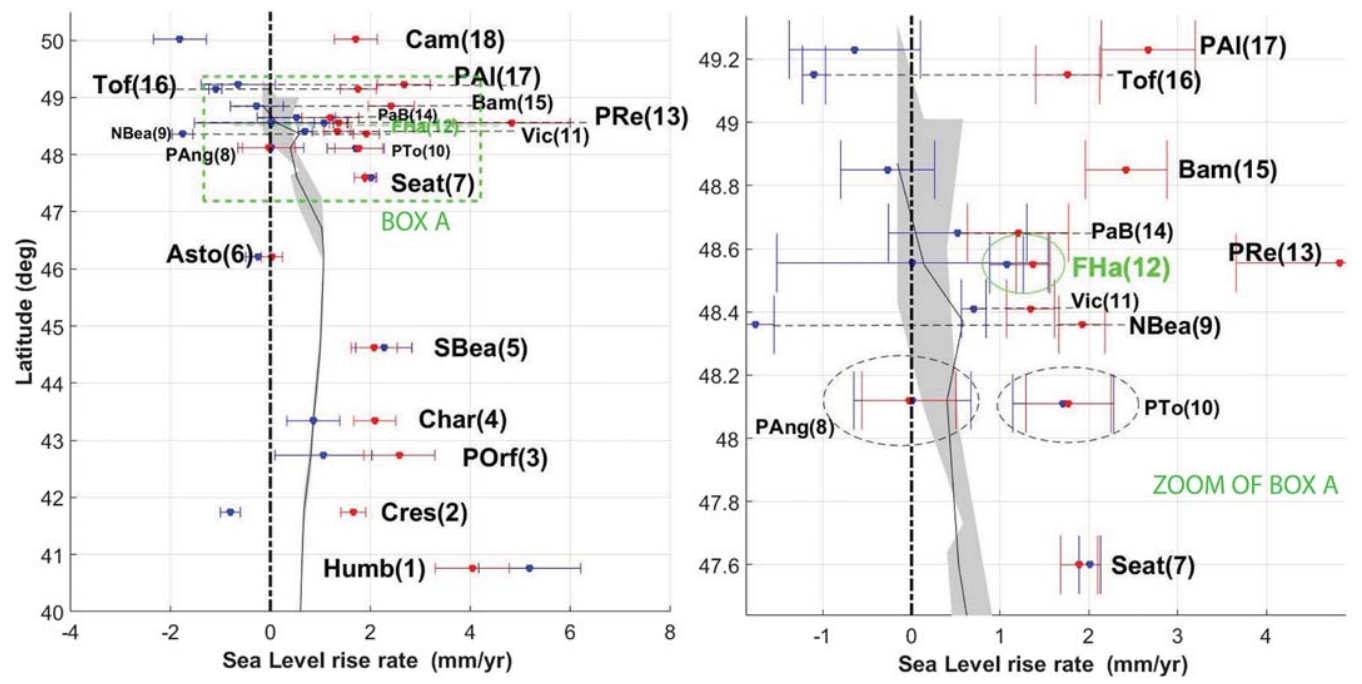

Figure 7. Red: uncorrected (biased by vertical land motion) Cascadia sea-level rise (SLR) rates estimated from long-term ( $\sim 50-100 \mathrm{yr}$ ) tide-gauge measurements; Blue: after correction for interpolated GPS-measured vertical land motion (absolute) at 18 tide gauges around the Pacific Northwest. Note that the full name of the tide gauges are displayed in Table 3. We display a zoom of the main figure (i.e., zoom of box A) due to a visual issue to separate the ones with close latitudes. The black line is the ensemble of GIA models from NRC (2015). Tide-gauge trends estimated with GGM noise model. 
PANGA GPS uplift velocities because of their far greater number and because stations included in both PANGA and PBO processing systems show no significant differences at the one sigma confidence interval.

Figure 7 shows (blue points) the absolute sea-level rise (ASLR) after correction for vertical land motion estimates, with ASLR uncertainties computed in quadrature from the separate GPS and RSLR uncertainties. Note that the GIA model displayed in this figure is extracted from NRC (2015). The VLM correction to the RSLR estimates accounts for both GIA and tectonic strain accumulation, and it is not generally possible to accurately isolate the two sources of uplift with imperfect knowledge of mantle viscosity, recent glaciation history, and interseismic coupling along the Cascadia megathrust fault. The GIA model displayed in Figure 7 is extracted from an ensemble of GIA models (NRC, 2015). Those GIA models include a contribution for changes in geocentric (absolute) sea level in addition to vertical land motion. Here it is shown simply to give the reader a general sense of what the GIA contribution to VLM might roughly be, and to quantify visually the VLM correction to RSLR.

Looking at Figure 7, it is striking the extent to which the highly scattered RSLR measurements coalesce, upon correction for VLM, to much tighter clustering around $2 \mathrm{~mm} / \mathrm{yr}$ of absolute sea-level rise throughout the greater Cascadia coastal region. Prior to correction the scatter of all RSLR measurements are $0.52 \pm$ $1.59 \mathrm{~mm} / \mathrm{yr}$, whereas after correction they $1.99 \pm 1.18 \mathrm{~mm} / \mathrm{yr}$, rates consistent with other twenty first century SLR rate measurements in the northeastern Pacific (e.g., Church et al., 2004; NRC, 2015; Wöppelmann et al., 2009). Regionally based on the ARMA estimates, along the outer Pacific coast of Washington State the ASLR rate is $1.36 \pm 0.76$ and $2.40 \pm 1.41 \mathrm{~mm} / \mathrm{yr}$ on Vancouver Island, also in agreement with, but to the higher end of, estimates of twentieth Century global mean sea-level rise (Church \& White, 2011). Along coastal Oregon ASLR averages $1.66 \pm 0.97 \mathrm{~mm} / \mathrm{yr}$, and for northern California $1.99 \pm 1.14 \mathrm{~mm} / \mathrm{yr}$. Overall, the drop in uncertainty suggests that accounting for vertical land motion absorbs much of the regional scatter in tide gauge-only SLR estimates. Figure 7 also profiles expected rebound associated with Glacial Isostatic Adjustment (GIA), drawn from an ensemble of models computed in NRC (2015), which suggest that roughly half the VLM on Vancouver Island arise from GIA and the rest from subduction-related strain accumulation. Table 2 provides all ASLR rates after VLM correction for each station as computed for ARMA, ARFIMA, and GGM noise models as well as associated metadata.

\section{Reference Frame Considerations}

One particular technical challenge in measuring VLM regionally pertains to creating an internally consistent, hemisphere-scale reference frame. Mazzotti et al. (2007) circumvented this issue by focusing only on a smaller region to the east of Vancouver Island and holding a single inland station, DRAO, fixed. This approach is not suitable for our analysis due to ubiquitous and readily measured continental deformation whose rates rival coastal VLM rates (Herring et al., 2016). In ITRF08, for instance, the reference station DRAO used by Mazzotti et al. (2007) has a radial velocity of $0.7 \pm 0.01 \mathrm{~mm} / \mathrm{yr}$ based on 27 years of continuous measurements.

Ideally, to be useful in long-term sea level studies, vertical land motion relative to Earth's center of mass should be determined with standard errors that are 1 order of magnitude lower than the contemporary climate signals of 1-3 mm/yr observed on average in sea-level records, either using tide gauges or satellites (Wöppelmann \& Marcos, 2016). Moreover, also required are tight constraints on the rate of offset between Earth's center of mass and Earth's center of figure, as defined by those GPS stations used to realize the reference frame, since any nonzero rate will produce a correlated bias in inferred sea-level rise rates over hemisphere spatial scales. Santamaría-Gómez et al. (2017) address this issue and conclude that Earth's center of figure is drifting $0 \pm 0.3 \mathrm{~mm} / \mathrm{yr}$ along the Earth's rotation axis. Nonzero motion would produce a latitudedependent bias between tide-guage SLR rates and their VLM correction as estimated by GPS within the ITRF reference frame. Center of mass position and rate of offset, which require combining observations from multiple techniques including VLBI, SLR, and GPS (e.g., Altamimi et al., 2011, 2016), comprise one current limitation in the realization of the terrestrial reference frame and has been identified as a geodesy Grand Challenge (Davis et al., 2012).

Other reference frame issues also arise over shorter intervals as well. For instance, the choice of whether to include a radial scaling degree of freedom during daily reference frame realization, which primarily impacts average network radial height, can also produce apparent height anomalies in excess of $5 \mathrm{~mm}$ that persist 


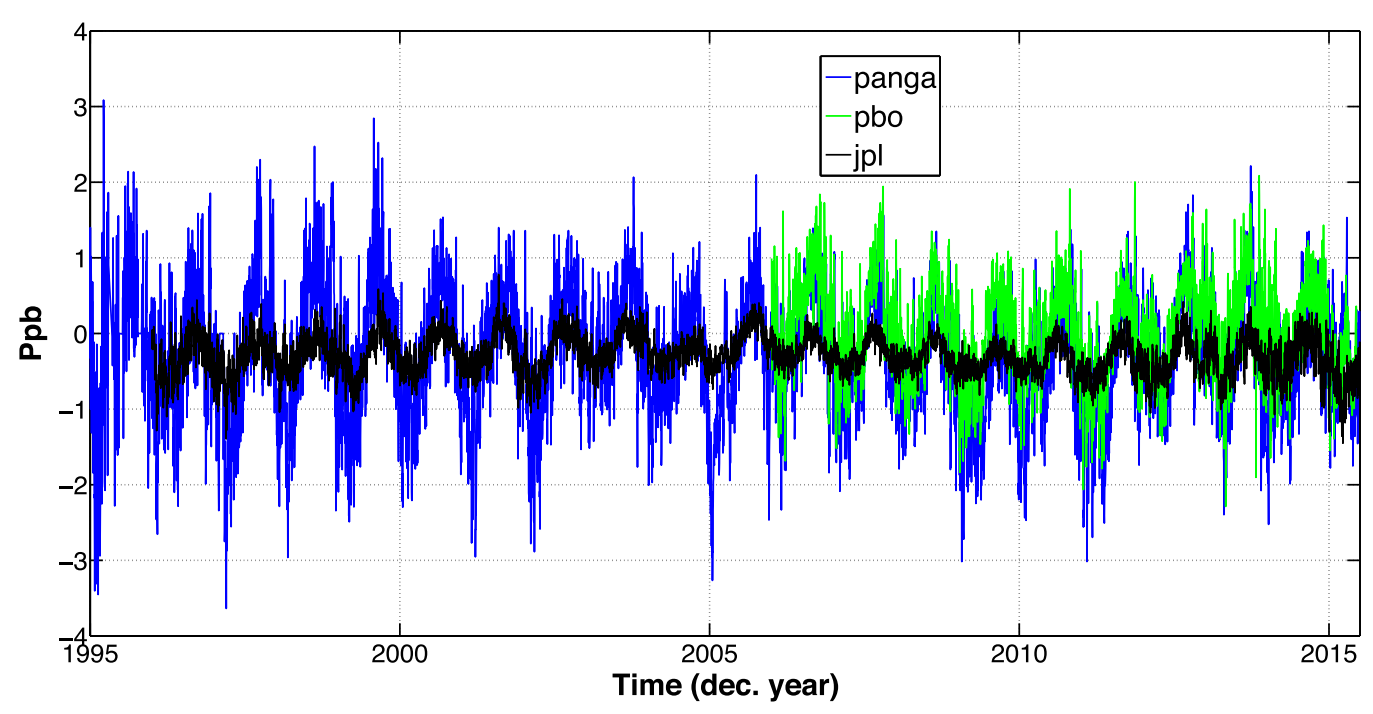

Figure 8. Scale in part per billions (ppb) estimated from PANGA processing (blue), PBO processing (green), and JPL X-files (black) derived from a global, not regional to North America. $1 \mathrm{ppm}$ of radial scale represents $\sim 6 \mathrm{~mm}$ of apparent vertical position change. PANGA and PBO scale estimates are based on North American-only GPS stations, and show similar amplitudes, whereas JPL scale is derived from global analyses which tends to suppress scale amplitude by averaging over broader areas that average out regional radial signals.

for months. Scale dates back to triangulation networks dependent on short baseline length measurements but is still commonly used due to differences arising from a variety of biases inherent in numerous different models and data sources used in GPS processing (Herring et al., 2016). The daily scale estimate thus may be considered as a proxy for the difference between the predicted and observed heights on any given day from the network centroid to Earth's center of mass. Since the radius of the Earth is approximately $6,371 \mathrm{~km}, 1 \mathrm{ppb}$ in scale translates into $\sim 6.3 \mathrm{~mm}$ of average network radial motion. The peak-to-peak amplitude of $4 \mathrm{ppb}$ seen in Figure 8, which shows scale from daily Helmert transformations over two decades as estimated with both regional and global analyses from PANGA (blue), PBO GAGE (green), and JPL (black) (Webb, 2004), is equivalent to $2.5 \mathrm{~cm}$ of vertical motion per year. The lower amplitude observed in the JPL scale is a result of the global station coverage used in their orbit processing, whereas both PANGA and PBO utilize only sites in the North American quadrant of the globe, thus amplifying the radial contribution from North American stations (Blewitt et al., 2001). Scale is often estimated, primarily to prevent the mapping of radial network motion into translational and rotational motions, but since it mimics average radial height, inclusion of scale during realization will absorb real regional vertical height variation so that it does not appear in geodetic time series, which can in turn lead to discrepancies in vertical rates. Figure 8 also shows that the scale rate averaged over two decades is close to zero, although its seasonal amplitude is strongly dependent on whether regional or global analyses are used, but nonetheless if this is not accounted for by being absorbed into the daily scale estimate it will appear as a bias in position time series that will impact estimated VLM rates.

More subtle difficulties also arise in reference frame definition that can also have first-order impacts on vertical rate estimates. For instance, routine GAGE analyses of the Plate Boundary Observatory data conducted with GAMIT (Herring et al., 2010) and GIPSY-Oasis ambiguity-resolved precise point positioning (Bertiger et al., 2010; Zumberge et al., 1997) show persistent aggregate station height differences of 5-10 mm despite identical definitions of the North American NAM08 reference frame. These differences arise because the double-differencing of raw GPS phase and range measurements to resolve satellite and receiver clock biases using only North American stations introduces position correlations that mimic scale changes and therefore apparent height biases. This particular problem is resolved in the Plate Boundary Observatory GAGE processing by including global stations well-outside the North American quadrant of the Earth during double-differencing (Herring et al., 2016). Precise point positioning in GIPSY-Oasis used in this study, by contrast, employs satellite clock, orbit, and wide-lane phase bias estimates all derived from global analyses and therefore are not as susceptible to this particular bias. 


\section{QAGU Journal of Geophysical Research: Oceans}

\section{Conclusions}

Apparent SLR rates vary spatially for numerous reasons that reflect both oceanic and solid-Earth processes. For instance, twentieth century rates for the western Pacific are more similar to twenty first century global rates (3.1 $\pm 0.7 \mathrm{~mm} / \mathrm{yr}$ ), whereas eastern Pacific satellite rates are significantly lower than the global mean value. Much of the west coast of the Americas actually show an apparent decrease in satellite geocentric sea surface height over the last 20 years (Church \& White, 2011). For TG measurements, many studies have also underlined how they are impacted by myriad processes that can vary from hemispherical, most notably the Pacific decadal oscillation, to spatially localized, and which may act over timescales over roughly a year to several decades. Such processes alter surface winds, ocean currents, temperature, and salinity, and, in turn sea level, all superimposed on long-term background sea-level rise (e.g., Cazenave et al., 2014; Church et al., 2004; Church \& White, 2011; IPCC, 2013; Nicholls \& Cazenave, 2010). For these reasons, tide gauges-based mean sea level exhibits much larger interannual variability than their altimetry-based global mean, but in general show coarse similarity to regional measurements reported by satellite altimetry (Prandi et al., 2009). In the Pacific Northwest, ASLR mean reported here of $1.36 \pm 0.75 \mathrm{~mm} / \mathrm{yr}$ is $\sim 20 \%$ smaller than the $1.7 \mathrm{~mm} / \mathrm{yr}$ global mean SLR from 1901 to 2010 (IPCC, 2013). However, if we take into account Vancouver Island, the ASLR is around $1.99 \pm 1.18 \mathrm{~mm} / \mathrm{yr}$ and thus $\sim 17 \%$ higher than the global mean SLR.

Twentieth century satellite geocentric ocean height rates also show a global mean of $1.5-1.9 \mathrm{~mm} / \mathrm{yr}$, or roughly half that of twenty first century rates of 3.2 [2.8-3.6] mm/yr, suggesting ongoing acceleration in sealevel rise rates (IPCC, 2013). The potential for late-twentieth century SLR rise acceleration complicates longterm forecasts and planning. Simple projection of constant rates from the past to predict future sea level impacts does not seem to be warranted given broader constraints on SLR (e.g., Cazenave and Le Cozannet, 2013; Church \& White, 2011; Nicholls \& Cazenave, 2010; Visser et al., 2015; Wenzel \& Schroter, 2014). Different hypotheses have been proposed with some scientists arguing that using historic rates to predict future trends is overly simplistic, given that the signal requires decades to become distinguishable from transient processes (e.g., Dangendorf et al., 2014; Haigh et al., 2014; Lyu et al., 2014). As a result, significant debate remains as to the best approach to both model sea-level rise from TG observations and predict its future rise in different regions over the next decades (e.g., Chandler \& Scott, 2011; Smith, 2002; Visser et al., 2015).

In the 18 tide-gauge data sets analyzed in this study, accelerations are not apparent or distinguishable from longterm rates. As described above, the AIC and BIC information criteria are used to select the parameters within the stochastic modeling (i.e., lags in the ARMA and ARFIMA), and whether the TG observations are fitted with a functional model that includes an acceleration along with the linear and seasonal signals, following Bos et al. (2014), is inconclusive. Primarily, no values of putative SLR accelerations rise above the formal uncertainties derived from the modeling. Hunter and Brown (2012) and Visser et al. (2015) pointed out various modeling approaches and assumptions to further tease out significant acceleration terms, but no acceleration signal within formal error may be isolated from the 18 Cascadia tide gauges by using fairly straightforward modeling approaches.

Financial support was provided by National Aeronautics and Space Administration Research Opportunities in Solid Earth Science grant NNXIOAD15G. Operations of the Pacific Northwest Geodetic Array, including archiving and daily analysis of GNSS data, was supported by the USGS National earthquake Hazards Reduction Program Cooperative agreement G15AC00062. Raw GPS observations from PANGA GPS stations can be downloaded at the website (http://www:panga:cwu:edu/data/ bysite/) for the PANGA stations and UNAVCO (ftp://data-out:unavco:org/ pub/products/position/) for the PBO(-NMT) stations. Data from the EarthScope Plate Boundary Observatory were used in this study. Tide-gauge time series are downloaded from the Permanent Service for Mean Sea Level (PMSL) website. We also acknowledge constructive comments from anonymous reviewers, which helped to improve this manuscript.
Ultimately, coastal communities will increasingly utilize sea-level rise projections to develop long-term adaptation and mitigation strategies in response to rising oceans. The Cascadia VLM profiles presented here vary smoothly over nearly $1,000 \mathrm{~km}$ of the NE Pacific coast and effectively remove a considerable amount of VLM uncertainty from long-term tide-gauge measurements of SLR rise. The average absolute SLR obtained after accounting for VLM yields, for coastal Cascadia, roughly $2 \mathrm{~mm} / \mathrm{yr}$, very similar to the $2 \mathrm{~mm} / \mathrm{yr}$ previously described with other global observations (e.g., Church et al., 2004; NRC, 2015). Within Puget Sound widespread subsidence identified with GPS shows that that rate of SLR will be exacerbated by widespread, but relatively slow, subsidence. For the rest of the world, the sheer numbers of GPS stations now available, over 16,000 globally (Blewitt et al., 2016), leave few coastlines unmeasured and suggest that using GPS-derived VLM profiles should be de rigueur in both correcting TG data and forecasting the impact of VLM on regional SLR for community mitigation purposes.

\section{References}

Akaike, H. (1974). A new look at the statistical model identification. IEEE Transactions on Automatic Control, 19(6), 716-723. https://doi.org/ 10.1109/TAC.1974.1100705

Altamimi, Z., Collilieux, X., \& Métivier, L. (2011). ITRF2008: An improved solution of the international terrestrial reference frame. Journal of Geodesy, 85(8), 457-473.

Altamimi, Z., Rebischung, P., Mtivier, L., \& Collilieux, X. (2016). ITRF2014: A new release of the International Terrestrial Reference Frame modeling nonlinear station motions. Journal of Geophysical Research: Solid Earth, 121, 6109-6131. https://doi.org/10.1002/ 2016JB013098 
Bertiger, W., Desai, S. D., Haines, B., Harvey, N., Moore, A. W., Owen, S., et al. (2010). Single receiver phase ambiguity resolution with GPS data. Journal of Geodesy, 84, 327-337. https://doi.org/10.1007/s00190-010-0371-9

Blewitt, G., \& Lavallée, D. (2002). Effect of annual signals on geodetic velocity. Journal of Geophysical Research: Solid Earth, 107(B7). https:// doi.org/10.1029/2001JB000570

Blewitt, G., Lavallée, D., Clarke, P., \& Nurutdinov, K. (2001). A new global mode of earth deformation: Seasonal cycle detected. Science, 294(5550), 2342-2345. https://doi.org/10.1126/science.1065328

Blewitt, G., Kreemer, C., Hammond, W. C., \& Gazeaux, J. (2016). MIDAS robust trend estimator for accurate GPS station velocities without step detection. Journal of Geophysical Research: Solid Earth, 121, 2054-2068. https://doi.org/10.1002/2015JB012552

Bos, M. S., Fernandes, R. M. S., Williams, S. D. P., \& Bastos, L. (2008). Fast error analysis of continuous GPS observations. Journal of Geodesy, 82(3), 157-166. https://doi.org/10.1007/s00190-007-0165-x

Bos, M. S., Fernandes, R. M. S., Williams, S. D. P., \& Bastos, L. (2013). Fast error analysis of continuous GNSS observations with missing data. Journal of Geodesy, 87(4), 351-360. https://doi.org/10.1007/s00190-012-0605-0

Bos, M. S., Araujo, I., \& Bastos, B. L. (2013b). Hector user manual version 1.1. Retrieved from http://segal.ubi.pt/hector/manual_1.6.pdf

Bos, M. S., Williams, S. D. P., Araujo, I. B., \& Bastos, L. (2014). The effect of temporal correlated noise on the sea level rate and acceleration uncertainty. Geophysical Journal International, 196, 1423-1430. https://doi.org/10.1093/gji/ggt481

Burgette, R. J., Weldon, R. J., \& Schmidt, D. A. (2009). Interseismic uplift rates for western Oregon and along-strike variation in locking on the Cascadia subduction zone. Journal of Geophysical Research: Solid Earth, 114, B01408. https://doi.org/10.1029/2008JB005679

Burgette, R. J., Watson, C. S., Church, J. A., White, N. J., Tregoning, P., \& Coleman, R. (2013). Characterizing and minimizing the effects of noise in tide gauge time series: Relative and geocentric sea level rise around Australia. Geophysical Journal International, 194, 719-736. https://doi.org/10.1093/gji/ggt131

Burnham, K. P., \& Anderson, D. R. (2002). Model selection and multimode inference: A practical information-theoretic approach (2nd ed.) New York, NY: Springer.

Cazenave, A., Dieng, H. B., Meyssignac, B., von Schuckmann, K., Decharme, B., \& Berthier, E. (2014). The rate of sea-level rise. Nature Climate Change, 4, 358-361. https://doi.org/10.1038/nclimate2159

Cazenave, A., \& Le Cozannet, G. (2013). Sea level rise and its coastal impacts. Earth's Future, 2, 15-34. https://doi.org/10.1002/ 2013 EF000188

Chandler, R. E., \& Scott, E. M. (2011). Statistical methods for trend detection and analysis in the environmental sciences (368 p.). Chichester, UK: John Wiley.

Church, J., White, N. J., Coleman, R., Lambeck, K., \& Mitrovica, J. X. (2004). Estimates of the regional distribution of sea level rise over the 1950 to 2000 period. Journal of Climate, 17(13), 2609-2625. https://doi.org/10.1175/1520-0442(2004)0172609:EOTRDO2.0.CO.2

Church, J. A., \& White, N. J. (2011). Sea-level rise from the late 19th century to the early 21st century. Surveys in Geophysics, 32(4-5), 585-602. https://doi.org/10.1007/s10712-011-9119-1

Dangendorf, S., Rybski, D., Mudersbach, C., Muller, A., Kaufmann, E., Zorita, E., et al. (2014). Evidence for long-term memory in sea level. Geophysical Research Letters, 41, 5530-5537. https://doi.org/10.1002/2014GL060538

Davis, J. L., Fialko, Y., Holt, W. E., Miller, M. M., Owen, S. E., \& Pritchard, M. E. (Eds.) (2012). A foundation for innovation: Grand challenges in Geodesy (Report from the Long-Range Science Goals for Geodesy Community Workshop, 79 p.). Boulder, CO: UNAVCO. Retrieved from https://www:unavco:org/communit/publicationsandreports/geodesyscienceplan/GrandChallengesInGeodesy-Final-Singles-LR:pdf

Douglas, B. C. (1991). Global sea level rise. Journal of Geophysical Research, 96(C4), 6981-6992. https://doi.org/10.1029/91JC00064

Dragert, H., Wang, K., \& James, T. S. (2001). A silent slip event on the deeper Cascadia subduction interface. Science, 292, 1525-1528. https://doi.org/10.1126/science.1060152

Haigh, I. D., Wahl, T., Rohling, E. J., Price, R. M., Pattiaratchi, C. B., Calafat, F. M., et al. (2014). Timescales for detecting a significant acceleration in sea level rise. Nature Communications, 5, 3635. https://doi.org/10.1038/ncomms4635

Hamlington, B. D., Thompson, P., Hammond, W. C., Blewitt, G., \& Ray, R. D. (2016). Assessing the impact of vertical land motion on twentieth century global mean sea level estimates. Journal of Geophysical Research: Oceans, 121, 4980-4993. https://doi.org/10.1002/2016JC011747

Hay, C. C., Marrow, E., Kopp, R. E., \& Mitrivica, J. X. (2015). Probabilistic reanalysis of twentieth-century sea-level rise. Nature, 517, 481-484. https://doi.org/10.1038/nature14093

He, X., Montillet, J.-P., Fernandes, R., Bos, M., Yu, K., \& Jiang, W. (2017). Review of current GPS methodologies for producing accurate time series and their error sources. Journal of Geodesy, 106, 12-29. https://doi.org/10.1016/j.jog.2017.01.004

He, X., Montillet, J.-P., Hua, X., Yu, K., Jiang, W., \& Zhou, F. (2016). Noise analysis for environmental loading effect on GPS time series. Acta Geodynamica et Geomaterialia, 14(185), 131-142. https://doi.org/10.13168/AGG.2016.0034

Herring, T. A., King, R. W., \& McClusky, S. C. (2010). Introduction to GAMIT/GLOBK (Report). Cambridge, UK: Massachusetts Institute of Technology.

Herring, T. A., King, R. W., McClusky, S. C., Floyd, M., Wang, L., Murray, M., et al. (2016). Plate boundary observatory and related networks: GPS data analysis methods and geodetic products. Reviews of Geophysics, 54, 759-808. https://doi.org/10.1002/2016RG000529

Hyndman, R. D., \& Wang, K. (1995). The rupture zone of Cascadia great earthquakes from current deformation and the thermal regime. Journal of Geophysical Research: Solid Earth, 100(B11), 22133-22154. https://doi.org/10.1029/95JB01970

Hunter, J. R., \& Brown, M. J. I. (2012). Discussion of Boretti, A., Is there any support in the long term tide gauge data to the claims that parts of Sydney will be swamped by rising sea levels? (Coastal Eng., 64, 161-167, June 2012). Coastal Engineering, 75, 1-3. https://doi.org/10. 1016/j.coastaleng.2012.12.003

IPCC (2013). Climate Change 2013: The physical science basis. In T. F. Stocker et al. (Eds.), Contribution of working group I to the fifths assessment report of the intergovernmental panel on climate change. Cambridge, UK: Cambridge University Press.

Klos, A., Bogusz, J., Figurski, M., \& Gruszczynski, M. (2015). Error analysis for European IGS stations. Studia Geophysica et Geodaetica, 60(1), 1-18. https://doi.org/10.1007/s11200-015-0828-7

Lambeck, K., \& Johnston, P. (1995). Land subsidence and sea-level change: Contributions from the melting of the last great ice sheets and the isostatic adjustment of the Earth. In F. B. J. Barends, F. J. J. Brouwer, \& F. H. Schroder (Eds.), Land subsidence-proceedings of the 5th international symposium on land subsidence (pp. 3-18). The Hague, Netherlands: Balkema.

Langbein, J. (2004). Noise in two-color electronic distance meter measurements revisited. Journal of Geophysical Research: Solid Earth, 109, B04406. https://doi.org/10.1029/2003JB002819

Langbein, J. (2008). Noise in GPS displacement measurements from Southern California and Southern Nevada. Journal of Geophysical Research: Solid Earth, 113, B05405. https://doi.org/10.1029/2007JB005247

Lyu, K., Zhang, X., Church, J. A., Slangen, A. B. A., \& Hu, J. (2014). Time of emergence for regional sea-level change. Nature Climate Change, 4, 1006-1010. https://doi.org/10.1038/nclimate2397 
Mao, A., Harrison, C. G., \& Dixon, T. H. (1999). Noise in GPS coordinate time series. Journal of Geophysical Research: Solid Earth, 104(B2), 2797-2816. https://doi.org/10.1029/1998JB900033

Mazzotti, S., Lambert, A., Courtier, N., Nykolaishen, L., \& Dragert, H. (2007). Crustal uplift and sea level rise in northern Cascadia from GPS, absolute gravity, and tide gauge data. Geophysical Research Letters, 34, L15306. https://doi.org/10.1029/2007GL030283

McCaffrey, R., King, R. W., Payne, S. J., \& Lancaster, M. (2013). Active tectonics of northwestern US inferred from GPS-derived surface velocities. Journal of Geophysical Research: Solid Earth, 118, 709-723. https://doi.org/10.1029/2012JB009473

McCaffrey, R., Qamar, A. I., King, R. W., Wells, R., Khazaradze, G., Williams, C. A., et al. (2007). Fault locking, block rotation and crustal deformation in the Pacific Northwest. Geophysical Journal International, 169, 1315-1340. https://doi.org/10.1111/j.365-246X.2007.03371.x

Melbourne, T. I., Szeliga, W. M., Miller, M., \& Santillan, V. M. (2005). Extent and duration of the 2003 Cascadia slow earthquake. Geophysical Research Letters, 32, L04301. https://doi.org/10.1029/2004GL021790

Meertens, C., Boler, F. M., Wier, S., Blewitt, G., Hammond, W. C., \& Kreemer, C. (2015). Plug and play GPS for earth scientists: Providing immediate access to low-latency geodetic products for rapid modeling and analysis of natural hazards. Fall Meeting 2015 (Abstract G11B0983). Washington, DC: American Geophysical Union. Retrieved from http://adsabs:harvard:edu/abs/2015AGUFM.G11B0983M

Miller, M. M., Dragert, H., Endo, E., Freymueller, J. T., Goldfinger, C., Kelsey, H. M., et al. (1998). PANGA: Precise measurements help gauge Pacific Northwest's Earthquake Potential. Eos Transactions, American Geophysical Union, 79(23), 269-275.

Miller, M. M., Melbourne, T. I., Johnson, D. J., \& Summer, W. Q. (2002). Periodic slow earthquakes from the Cascadia subduction zone. Science, 295(5564), 2423. https://doi.org/10.1126/science.1071193

Mitrovica, J. X., \& Davis, J. L. (1995). Present-day post-glacial sea level change far from the late Pleistocene ice sheets: Implications for recent analyses of tide gauge records. Geophysical Research Letters, 22(18), 2529-2532. https://doi.org/10.1029/95GL02240

Montillet, J. P., Williams, S. D. P., Koulali, A., \& McClusky, S. C. (2015). Estimation of offsets in GPS time-series and application to the detection of earthquake deformation in the far-field. Geophysical Journal International, 200, 1205-1219. https://doi.org/10.1093/gji/ ggu473

Montillet, J. P., \& Yu, K. (2015). Modelling geodetic processes with Levy alpha-stable distribution. Mathematical Geosciences, 47(6), 627-646. https://doi.org/10.1007/s11004-014-9574-6

National Research Council Report (NRC) (2015). Sea-level rise for the coasts of California, Oregon, and Washington: Past, present, and future. Washington, DC: The National Academies Press. Retrieved from www:nap:edu/catalog:php?recordid=513389

Nicholls, R. J., \& Cazenave, A. (2010). Sea-level rise and its impact on coastal zones. Science, 328(5985), 1517-1520. https://doi.org/10.1126/ science. 1185782

Panas, E. (2001). Estimating fractal dimension using stable distributions and exploring long memory through ARFIMA models in Athens Stock Exchange. Applied Financial Economics, 11(4), 395-402. https://doi.org/10.1080/096031001300313956

Prandi, P., Cazenave, A., \& Becker, M. (2009). Is coastal mean sea level rising faster than the global mean? A comparison between tide gauges and satellite altimetry over 1993-2007. Geophysical Research Letters, 36, L05602. https://doi.org/10.1029/2008GL036564

Ray, R. D., \& Douglas, B. C. (2011). Experiments in reconstructing twentieth-century sea levels. Progress in Oceanography, 91, 496-515. doi.org/10.1016/j.pocean.2011.07.021

Rickards, L. J. (2015). Report by the Permanent Service for Mean Sea Level (PSMSL) for the Period 2011-2015 to the XXVI General Assembly of the IUGG, Prague, Czech Republic, June/July.

Santamaría-Gómez, A., Bouin, M. N., Collilieux, X., \& Wöppelmann, G. (2011). Correlated errors in GPS position time series: Implications for velocity estimates. Journal of Geophysical Research: Solid Earth, 116, B01405. https://doi.org/10.1029/2010JB007701

Santamaría-Gómez, A., Gravelle, M., Dangendorf, S., Marcos, M., Spada, G., \& Wöppelmann, G. (2017). Uncertainty of the 20th century sealevel rise due to vertical land motion errors. Earth and Planetary Science Letters, 473, 24-32. doi.org/10.1016/j.epsl.2017.05.038

Savage, J. C., \& Lisowski, M. (1991). Strain measurements and the potential for a Great Subduction earthquake off the Coast of Washington. Science, 252(5002), 101-103.

Schwarz, G. (1978). Estimating the dimension of a model. Annals of Statistics, 6(2), 461-464.

Smith, R. A. (2002). Historical golden gate tidal series (NOAA Tech. Rep., NOS CO-OPS 035). Silver Spring, MD: National Oceanic and Atmospheric Administration.

Sweet, W., Park, J., Marra, J., Zervas, C., \& Gill, S. (2014). Sea level rise and nuisance flood frequency change around the Unites States (Tech. Rep. NOS CO-OPS 073). Silver Spring, MD: National Oceanic and Atmospheric Administration (NOAA). Retrieved from http://tidesandcurrents:noaa:gov/publications/NOAATechnicalReportNOSCOOPS073:pdf

Szeliga, W., Melbourne, T., Santillian, V., \& Miller, M. (2008). GPS constraints on 34 slow slip events in the Cascadia subduction zone, 1997-2005. Journal of Geophysical Research: Solid Earth, 113, B04404. https://doi.org/10.1029/2007JB004948

UNAVCO (2009). Plate Boundary Observatory: The first five years. Boulder, CO: UNAVCO. Retrieved from https://www.unavco.org/ education/outreach/pamphlets/2009-PBO/PBO-2009-brochure-first-five-years.pdf

Visser, H., Dangendorf, S., \& Petersen, A. C. (2015). A review of trend models applied to sea level data with reference to the acceleration deceleration debate. Journal of Geophysical Research: Oceans, 120, 3873-3895. https://doi.org/10.1002/2015JC010716

Webb, F. (2004). SCIGN REASoN CAN update. Annual meeting update report. Retrieved from http://sopac.ucsd.edu/input/reason/presentations/JPLUpdateSCIGNCB2004.ppt

Wenzel, M., \& Schroter, J. (2014). Global and regional sea level change during the 20th century. Journal of Geophysical Research: Oceans, 119, 7493-7508. https://doi.org/10.1002/2014JC009900

Williams, S. D., Bock, Y., Fang, P., Jamason, P., Nikolaidis, R. M., Prawirodirdjo, L., et al. (2004). Error analysis of continuous GPS position time series. Journal of Geophysical Research: Solid Earth, 109, B03412. https://doi.org/10.1029/2003JB002741

Williams, S. D. P. (2003a). The effect of coloured noise on the uncertainties of rates estimated from geodetic time series. Journal of Geodesy, 76, 483-494. https://doi.org/10.1007/s00190-002-0283-4

Williams, S. D. P. (2003b). Offsets in Global Positioning System time series. Journal of Geophysical Research: Solid Earth, 108 (B6), 2310. https://doi.org/10.1029/2002JB002156

Wilson, D. S. (1993). Confidence intervals for motion and deformation of the Juan de Fuca plate. Journal of Geophysical Research: Solid Earth, 98(B9), 16053-16071. https://doi.org/10.1029/93JB01227

Wöppelmann, G., Letetrel, C., Santamaria, A., Bouin, M.-N., Collilieux, X., Altamimi, Z., et al. (2009). Rates of sea-level change over the past century in a geocentric reference frame. Geophysical Research Letters, 36, L12607. https://doi.org/10.1029/2009GL038720

Wöppelmann, G., \& Marcos, M. (2016). Vertical land motion as a key to understanding sea level change and variability. Reviews of Geophysics, 54, 64-92. https://doi.org/10.1002/2015RG000502

Wöppelmann, G., Martin Miguez, B., Bouin, M.-N., \& Altamimi, Z. (2007). Geocentric sea-level trend estimates from GPS analyses at relevant tide gauges world-wide. Global Planetary Change, 57, 396-406. https://doi.org/10.1016/j.gloplacha.2007.02.002 
Zhang, J., Bock, Y., Johnson, H., Fang, P., Williams, S., Genrich, J., et al. (1997). Southern California Permanent GPS geodetic array: Error analysis of daily position estimates and site velocities. Journal of Geophysical Research: Solid Earth, 102(B8), 18035-18055. https://doi.org/10. 1029/97JB01380

Zumberge, J. F., Heflin, M. B., Jefferson, D. C., Watkins, M. M., \& Webb, F. H. (1997). Precise point positioning for the efficient and robust analysis of GPS data from large networks. Journal of Geophysical Research: Solid Earth, 102(B3), 5005-5017. https://doi.org/10.1029/ 96JB03860 